\title{
Thiol-Ene Networks from Sequence-Defined Polyurethane Macromers
}

Emily A. Hoff ${ }^{1}$, Guilhem X. De Hoe ${ }^{2}$, Christopher M. Mulvaney ${ }^{1}$, Marc A. Hillmyer ${ }^{2}$, Christopher A. Alabi $^{1 *}$

${ }^{1}$ Robert Frederick Smith School of Chemical \& Biomolecular Engineering, 120 Olin Hall, Cornell University, Ithaca, NY 14835 USA

${ }^{2}$ Department of Chemistry, University of Minnesota, 207 Pleasant Street SE, Minneapolis, Minnesota 55455-0431, United States

Contents

Page

Materials and Methods

Supplementary Table 1. Expected and observed masses via LC-MS for each step in SD-PU oligomer synthesis

Supplementary Figure 1. Absorbance spectra of each SD-PUM at $260 \mathrm{~nm}$

Supplementary Figure 2-4. ${ }^{13} \mathrm{C}$ NMR spectrum of each SD-PU oligomer

Supplementary Equation 1. Eyring equation

Supplementary Figure 5-7. ROESY 2D ${ }^{1} \mathrm{H}$ NMR spectra of each SD-PU oligomer

Supplementary Figure 8-10. Variable temperature ${ }^{1} \mathrm{H}$ NMR spectra of each SD-PU oligomer .....

Supplementary Figure 11. Thermograms of TGA experiments for each SD-PU oligomer

Supplementary Figure 12-14. ${ }^{1} \mathrm{H}$ NMR spectra for the thiol-ene reaction of each oligomer with EEET at $0,1,3,5,10,15$, and 60 min.

Supplementary Figure 15. Gel fraction analyses (gravimetric) for SD-PUM-EDET networks........ 16

Supplementary Figure 16. Gel fraction analyses (fluorescence) for SD-PUM-EBMA networks...... 16

Supplementary Figure 17. DSC of networks formed with EDET (A) or EBMA (B) .................... 18

Supplementary Figure 18. Pictures of the mAmAmA-network prepared for mechanical testing..... 18

Supplementary Figure 19-20. Frequency and strain sweeps at $150{ }^{\circ} \mathrm{C}$ of SD-PUM-EDET networks via tensile rheology

Supplementary Figure 21-22. Frequency and strain sweeps at $150{ }^{\circ} \mathrm{C}$ of SD-PUM-EBMA networks via tensile rheology

Supplementary Figure 23. Average storage moduli from frequency sweeps at $150{ }^{\circ} \mathrm{C}$.

Supplementary Figure 24. Absorbance spectra $(210 \mathrm{~nm})$ from LC-MS analysis of sol fractions...... 23

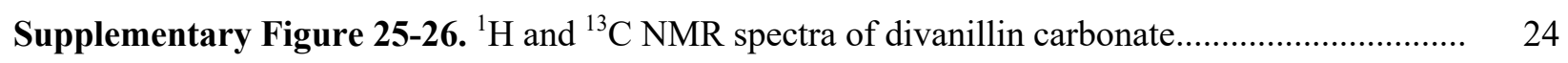

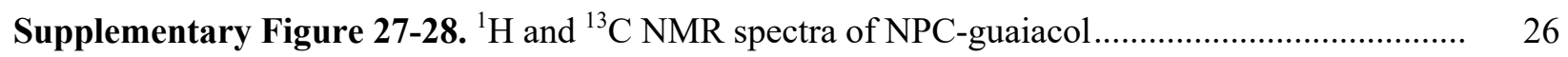

Supplementary Figure 29-30. ${ }^{1} \mathrm{H}$ and ${ }^{13} \mathrm{C}$ NMR spectra of 3,4-dimethoxy-N-methylbenzylamine (MBA)

Supplementary Figure 31-32. ${ }^{1} \mathrm{H}$ and ${ }^{13} \mathrm{C}$ NMR spectra of 3,4-dimethoxy-N-allylbenzylamine (ABA)

Supplementary Figure 33-34. ${ }^{1} \mathrm{H}$ NMR and ${ }^{13} \mathrm{C}$ NMR spectra of EEET synthesized for model thiol kinetics 
Materials. All solvents and aqueous ammonium hydroxide solution (28-30 w/w\%) were obtained from Fisher Scientific and used as received. The following reagents were also used as received: vanillin (99\%, Alfa Aesar), triethylamine (Aldrich), 4-nitrophenyl chloroformate (Oakwood), guaiacol (TCI), 4-dimethylaminopyridine (DMAP, Aldrich), 2,2'-(ethylenedioxy)diethanethiol (EDET, 95\%, Aldrich), ethane-1,2-diyl bis(2-mercaptoacetate) (EBMA, EMD Millipore), 2,2dimethoxy-2-phenylacetophenone (DMPA, Aldrich), methylamine (2M in THF, Aldrich), allylamine (Aldrich), acetonitrile-d3 (Aldrich), chloroform-d (Cambridge Isotopes). 2-(2ethoxyethoxy)ethane-1-thiol (EEET) used for monothiol kinetic experiments was synthesized according to an adapted literature procedure described below.

Characterization. NMR spectroscopy was conducted on a Bruker $500 \mathrm{MHz}$ NMR spectrometer equipped with a cryoprobe for $1 \mathrm{D}$ and variable temperature experiments and a Varian INOVA $600 \mathrm{MHz}$ spectrometer for 2D ROESY experiments. 2D ROESY spectra were collected at $0 \mathrm{~ms}$ and $200 \mathrm{~ms}$ mixing times for each oligomer and exchange rate constants were calculated using EXSY CALC by Mestrelab research NMR solutions. Differential scanning calorimetry (DSC) was performed using Mettler-Toledo Polymer DSC instrument equipped with a chiller and an autosampler. Samples were prepared in aluminum pans and analyzed with the following heat/cool profile $\left(10{ }^{\circ} \mathrm{C} / \mathrm{min}\right.$ ramp rates): (1) isotherm at $-30{ }^{\circ} \mathrm{C}$ for $10 \mathrm{~min},(2)-30{ }^{\circ} \mathrm{C}$ to $150{ }^{\circ} \mathrm{C}$, (3) $150{ }^{\circ} \mathrm{C}$ to $30^{\circ} \mathrm{C}$, (4) isotherm at $-30{ }^{\circ} \mathrm{C}$ for $10 \mathrm{~min}$, and $(5)-30{ }^{\circ} \mathrm{C}$ to $150{ }^{\circ} \mathrm{C}$. Glass transition temperatures were obtained from the second heating cycle. TGA experiments were carried out in air with a TA Instruments Q500 Thermogravimetric analyzer from $30^{\circ} \mathrm{C}$ to $550^{\circ} \mathrm{C}$ with a ramp rate of $10{ }^{\circ} \mathrm{C} / \mathrm{min}$. UV-Vis and fluorescence measurements were performed with a TECAN Infinite M1000 PRO Microplate reader. Fluorescence intensities for sol fraction measurements were recorded at $306 \mathrm{~nm}$ after excitation at $270 \mathrm{~nm}$. Liquid chromatography-mass spectrometry (LC-MS) experiments were carried out on an Agilent 1100 Series LC/MSD equipped with a Jupiter ${ }^{\circledR} 5 \mu \mathrm{m} \mathrm{C4} 300 \AA$ LC column $(50 \times 2 \mathrm{~mm}$, reversed phase), UV diode-array detector monitoring $210 \mathrm{~nm}, 230 \mathrm{~nm}, 260 \mathrm{~nm}, 360 \mathrm{~nm}$, and $505 \mathrm{~nm}$ wavelengths, and Agilent multimode source. Water with $0.1 \%$ acetic acid (solvent $\mathrm{A}$ ) and acetonitrile with $0.1 \%$ acetic acid (solvent B) were used as LC-MS eluents. Compounds were eluted at a flow rate of $1.0 \mathrm{~mL} / \mathrm{min}$ with a linear gradient of 5\% to $100 \%$ solvent B over 10 minutes, then constant at $100 \%$ solvent B for 2 min before equilibrating the column back to $5 \%$ solvent $\mathrm{B}$ over $3 \mathrm{~min}$; all masses were detected in positive ion mode. DART-HRMS was performed in positive ion mode at $200{ }^{\circ} \mathrm{C}$ on a Thermo Scientific Exactive Orbitrap MS system with an Ion Sense DART ion source. Column chromatography was carried out with a Teledyne CombiFlash ${ }^{\circledR} \mathrm{Rf}^{+}$Lumen automated flash chromatography system. UV irradiation for the thiol-ene reaction was performed with a BlueWave ${ }^{\circledR} 75$ UV curing spot lamp (Dymax Corporation).

Dynamic mechanical thermal analysis (DMTA) was performed using a TA instruments RSA-G2 analyzer with rectangular specimens cut with a razor blade [Supplementary Figure 16, ca. 0.7 $\mathrm{mm}(\mathrm{T}) \times 3 \mathrm{~mm}(\mathrm{~W}) \times 20 \mathrm{~mm}(\mathrm{~L})]$ in a tensile geometry. The sample was clamped loosely in the fixture at first to avoid breaking the films. The sample then was heated to $150{ }^{\circ} \mathrm{C}$ and the axial force was continuously adjusted to $0.05 \mathrm{~N}$ (sensitivity $0.01 \mathrm{~N}$ ) to ensure the sample was kept in tension and no buckling occurred. The sample was equilibrated at $150{ }^{\circ} \mathrm{C}$ for 5 min before adjusting the fixture while heated to hold the sample securely. After adjusting the fixture, the axial force adjust was reapplied and the sample was equilibrated at $150{ }^{\circ} \mathrm{C}$ for another 5 min before beginning experiments. For frequency sweeps $\left(0.1\right.$ to $\left.100 \mathrm{rad} \mathrm{s}^{-1}\right)$, the sample was kept at 
$0.5 \%$ strain and a constant temperature of $150{ }^{\circ} \mathrm{C}$. For strain sweeps $(0.01 \%$ to $1 \%)$, the frequency was set to $6.28 \mathrm{rad} \mathrm{s}^{-1}$ and the temperature was again held at $150{ }^{\circ} \mathrm{C}$. Temperature sweeps at a constant frequency $\left(6.28 \mathrm{rad} \mathrm{s}^{-1}\right)$ were started at $150{ }^{\circ} \mathrm{C}$ and the sample was cooled at a rate of $5{ }^{\circ} \mathrm{C} \mathrm{min}^{-1}$ to $40{ }^{\circ} \mathrm{C}$. The proportional force mode was set to force tracking to maintain an axial force that was at least $100 \%$ greater than the dynamic oscillatory force. The strain adjust was set to $30 \%$ with minimum and maximum strain values of $1 \times 10^{-3} \%$ and $10 \%$ and minimum and maximum forces of $0.01 \mathrm{~N}$ and $0.2 \mathrm{~N}$, respectively.

General Procedure for the Synthesis of Sequence-Defined Polyurethane Macromers (SD-PUM). SD-PU oligomers were synthesized by a series of sequential reductive aminations and carbamations. To start, 3,4-dimethoxybenzaldehyde was reacted with a primary amine (either allylamine or methyl amine) to form a secondary amine following the general method for reductive amination below. After this step, alternating carbamate reactions with divanillin carbonate and reductive aminations with either methyl- or allylamine were used to construct each sequence-defined oligomer as shown in Figure 1.

General Method for Reductive Amination Reactions. Aldehyde-terminated oligomer precursor (1 equiv.) was dissolved in minimal methanol. A primary amine monomer (methyl- or allylamine, 2.5 equiv.) and a small portion of $\mathrm{Na}_{2} \mathrm{SO}_{4}$ was added to the solution. The reaction was stirred at room temperature for $2.5 \mathrm{~h}$ before removing the $\mathrm{Na}_{2} \mathrm{SO}_{4}$ by decanting. The flask was then cooled to $0^{\circ} \mathrm{C}$, sodium borohydride was added ( 0.6 equiv.), and the reaction vented immediately. After $15 \mathrm{~min}$, the reaction was brought to room temperature and stirred for $1 \mathrm{~h}$. The reaction was quenched with water and the product extracted with dichloromethane (3 X $50 \mathrm{~mL}$ ). The extracted organic portions were combined and dried over $\mathrm{Na}_{2} \mathrm{SO}_{4}$. Solvent was removed via rotary evaporation to yield the product as an oil or a foamy powder depending on molar mass. For 11mer synthesis, the product was purified by column chromatography with a gradient of $0-20 \%$ methanol in DCM over $30 \mathrm{~min}$. All reductive amination products were used without further purification after extraction. Typical recovered yields for the reductive amination steps were $\geq$ $80 \%$.

General Method for Carbamation Reactions. Secondary amine-terminated oligomer precursor (1 equiv.) and triethylamine (1.1 equiv.) were combined in minimal acetonitrile and heated to $50^{\circ} \mathrm{C}$. Divanillin carbonate (1.1 equiv.) was added, and the reaction was stirred for $3 \mathrm{~h}$ (terminal methyl substituents) or $6 \mathrm{~h}$ (terminal allyl substituents). The reaction mixture was concentrated, dissolved in dichloromethane $(25 \mathrm{~mL})$, and ammonium hydroxide $(100 \mathrm{~mL})$ was added to degrade residual divanillin carbonate into water-soluble byproducts. The reaction mixture was extracted with dichloromethane $(3 \times 50 \mathrm{~mL})$. The combined organic layers were washed with 1 $\mathrm{M} \mathrm{HCl}(2 \times 50 \mathrm{~mL})$, sat. $\mathrm{NaHCO}_{3}(2-3 \times 50 \mathrm{~mL})$, and brine $(1 \times 50 \mathrm{~mL})$. The organic layer was dried over $\mathrm{Na}_{2} \mathrm{SO}_{4}$ and concentrated to yield the product as an oil or foamy powder depending on molar mass. All carbamation reaction products were used without further purification after extraction. Typical recovered yields for carbamation steps were $\geq 80 \%$.

End-Capping Reaction with 4-Nitrophenol-Activated Guaiacol. In the final step, secondary amine-terminated 11-mer (1 equiv.), triethylamine (1.1 equiv.), and 4-dimethylaminopyridine $(20 \mathrm{~mol} \%)$ were dissolved in acetonitrile $(50 \mathrm{~mL})$ and heated to $50^{\circ} \mathrm{C}$. 4-Nitrophenol-activated guaiacol (1.1 equiv.) was added and the same protocol for carbamation reaction and purification 
was followed. Finally, the product was concentrated and further purified by column chromatography with a gradient of $0-20 \%$ methanol in DCM. The final product was obtained as a white, foamy powder.

Synthesis of Divanillin Carbonate (DVC). Vanillin (138.2 g, 0.91 mol, 5.0 equiv.) and triethylamine (38.0 mL, 0.27 mol, 1.5 equiv.) were dissolved in DCM (500 mL) in a 1-L round bottom flask equipped with an addition funnel. Once cooled to $0{ }^{\circ} \mathrm{C}$, a solution of 4-Nitrophenyl chloroformate (36.6 g, $0.18 \mathrm{~mol}, 1.0$ equiv.) dissolved in dichloromethane (DCM, $100 \mathrm{~mL}$ ) was added dropwise over $1 \mathrm{~h}$. The reaction was stirred for $18 \mathrm{~h}$ and then washed with $1 \mathrm{M} \mathrm{HCl}(1 \mathrm{x}$ $300 \mathrm{~mL})$, saturated $\mathrm{NaHCO}_{3}(2 \times 300 \mathrm{~mL})$, and brine $(1 \times 300 \mathrm{~mL})$. The organic layer was dried over $\mathrm{Na}_{2} \mathrm{SO}_{4}$ before the solvent was removed by rotary evaporation. The yellow solid was then triturated twice with diethyl ether to yield divanillin carbonate $(48.0 \mathrm{~g}, 80 \%)$ as a white solid. ${ }^{1} \mathrm{H}$ NMR $\left(500 \mathrm{MHz}, \mathrm{CDCl}_{3}\right) \delta 9.95(\mathrm{~s}, 1 \mathrm{H}), 7.51(\mathrm{dd}, J=19.1,1.8 \mathrm{~Hz}, 2 \mathrm{H}), 7.41(\mathrm{~d}, J=8.0 \mathrm{~Hz}$, $1 \mathrm{H}), 3.97(\mathrm{~s}, 3 \mathrm{H}) .{ }^{13} \mathrm{C} \mathrm{NMR}\left(126 \mathrm{MHz}, \mathrm{CDCl}_{3}\right) \delta 190.95,151.95,149.92,144.66,135.74$, 124.65, 122.91, 111.34, 56.41. HRMS (DART) $\mathrm{m} / \mathrm{z}$ calculated for $\mathrm{C}_{17} \mathrm{H}_{14} \mathrm{O}_{7}(\mathrm{M})^{+} 330.07395$, found 330.07434 (error $1.16 \mathrm{ppm}$ ).

Synthesis of 4-Nitrophenyl-Activated Guaiacol (NPC-guaiacol). Guaiacol (0.0858 g, $6.91 \mathrm{mmol}$, 1.0 equiv.) and triethylamine (1.16 mL, $8.30 \mathrm{mmol}, 1.5$ equiv.) were dissolved in $\mathrm{DCM}$ and cooled to $0{ }^{\circ} \mathrm{C}$. 4-Nitrophenyl chloroformate ( $1.394 \mathrm{~g}, 6.91 \mathrm{mmol}, 1.0$ equiv.) was dissolved in $\operatorname{DCM}(5 \mathrm{~mL})$ and added dropwise over $30 \mathrm{~min}$ before warming the reaction to room temperature and stirring for $3 \mathrm{~h}$. The organic layer was then washed with $1 \mathrm{M} \mathrm{HCl}(1 \times 50 \mathrm{~mL})$, saturated $\mathrm{NaHCO}_{3}(2 \times 50 \mathrm{~mL})$, and brine $(1 \times 50 \mathrm{~mL})$ and dried over $\mathrm{Na}_{2} \mathrm{SO}_{4}$. The solvent was removed by rotary evaporation and the yellow solid was washed with cooled diethyl ether until the product was obtained as a white crystalline solid $(1.40 \mathrm{~g}, 70.2 \%) .{ }^{1} \mathrm{H} \mathrm{NMR}\left(500 \mathrm{MHz}, \mathrm{CDCl}_{3}\right) \delta$ $8.35-8.28(\mathrm{~d}, 2 \mathrm{H}), 7.54-7.47(\mathrm{~d}, 2 \mathrm{H}), 7.30(\mathrm{td}, J=7.8,1.6 \mathrm{~Hz}, 1 \mathrm{H}), 7.25(\mathrm{dd}, J=8.0,1.6 \mathrm{~Hz}$, $1 \mathrm{H}), 7.08-6.98(\mathrm{~m}, 2 \mathrm{H}), 3.93(\mathrm{~s}, 3 \mathrm{H}) .{ }^{13} \mathrm{C} \mathrm{NMR}\left(126 \mathrm{MHz}, \mathrm{CDCl}_{3}\right) \delta 155.55,150.88,150.57$, $145.52,139.71,127.83,125.37,122.05,121.71,120.88,112.74,56.03$. HRMS (DART) $\mathrm{m} / \mathrm{z}$ calculated for $\mathrm{C}_{14} \mathrm{H}_{11} \mathrm{NO}_{6}(\mathrm{M})^{+} 289.05864$, found 289.05894 (error $1.04 \mathrm{ppm}$ ).

Synthesis of 3,4-dimethoxy-N-methylbenzylamine (MBA). In a typical reaction, 3,4dimethoxybenzaldehyde ( $8.25 \mathrm{~g}, 49.7 \mathrm{mmol}, 1.0$ equiv.) was dissolved in minimal methanol and methylamine (2 M solution in THF) (49.7 mL, $99.3 \mathrm{mmol}, 2.0$ equiv.). A small portion of $\mathrm{Na}_{2} \mathrm{SO}_{4}$ was added and the reaction was gently stirred for $2.5 \mathrm{~h}$ at room temperature. The solution was then decanted into another round bottom flask to remove most of the $\mathrm{Na}_{2} \mathrm{SO}_{4}$, cooled to $0{ }^{\circ} \mathrm{C}$ in an ice bath, $\mathrm{NaBH}_{4}(1.13 \mathrm{~g}, 29.8 \mathrm{mmol}, 0.6$ equiv.) was added, and the reaction was vented with a needle immediately. After $10 \mathrm{~min}$, the ice bath was removed, and the reaction allowed to proceed for $1 \mathrm{~h}$ after reaching room temperature. Upon completion, the reaction mixture was quenched with water and the product was extracted with DCM (3 x $50 \mathrm{~mL})$. The combined layers of DCM were dried over $\mathrm{Na}_{2} \mathrm{SO}_{4}$ and solvent removed via rotary evaporation to yield the product as a clear oil $(8.31 \mathrm{~g}, 92.3 \%$ yield $) .{ }^{1} \mathrm{H} \mathrm{NMR}\left(500 \mathrm{MHz}, \mathrm{CDCl}_{3}\right) \delta 6.87(\mathrm{~d}, J=$ $1.8 \mathrm{~Hz}, 1 \mathrm{H}), 6.83-6.77(\mathrm{~m}, 2 \mathrm{H}), 3.86(\mathrm{~s}, 3 \mathrm{H}), 3.84(\mathrm{~s}, 3 \mathrm{H}), 3.66(\mathrm{~s}, 2 \mathrm{H}), 2.43(\mathrm{~s}, 3 \mathrm{H}) .{ }^{13} \mathrm{C} \mathrm{NMR}$ $\left(126 \mathrm{MHz}, \mathrm{CDCl}_{3}\right) \delta 148.96,148.03,132.75,120.27,111.36,110.94,55.90,55.83,36.00$. HRMS (DART) m/z calculated for $\mathrm{C}_{10} \mathrm{H}_{15} \mathrm{NO}_{2}(\mathrm{M})^{+} 181.11028$, found 181.11036 (error 0.42 ppm). 
Synthesis of 3,4-dimethoxy-N-allylbenzylamine (ABA). Similar to MBA synthesis, ABA was synthesized by dissolving 3,4-dimethoxybenzaldehyde (16.0 g, $96.5 \mathrm{mmol}, 1.0 \mathrm{equiv}$.) and allylamine (14.4 mL, $193.1 \mathrm{mmol}, 2.0$ equiv.) in minimal methanol. A small portion of $\mathrm{Na}_{2} \mathrm{SO}_{4}$ was added and the reaction was gently stirred for $2.5 \mathrm{~h}$ at room temperature. After $2 \mathrm{~h}$, the solution was decanted into another round bottom flask to remove most of the $\mathrm{Na}_{2} \mathrm{SO}_{4}$, cooled to $0{ }^{\circ} \mathrm{C}$ in an ice bath, $\mathrm{NaBH}_{4}(2.19 \mathrm{~g}, 57.9 \mathrm{mmol}, 0.6$ equiv.) was added, and the reaction was vented with a needle immediately. After $10 \mathrm{~min}$, the ice bath was removed, and the reaction allowed to proceed for $1 \mathrm{~h}$ after reaching room temperature. Upon completion, the reaction mixture was quenched with water and the product was extracted with DCM (3 x $50 \mathrm{~mL})$. The combined layers of DCM were dried over $\mathrm{Na}_{2} \mathrm{SO}_{4}$ and solvent removed via rotary evaporation to yield the product as a clear oil $\left(17.5 \mathrm{~g}, 87.5 \%\right.$ recovery). ${ }^{1} \mathrm{H}$ NMR $\left(500 \mathrm{MHz}, \mathrm{CDCl}_{3}\right) \delta 6.89(\mathrm{~d}$, $J=1.9 \mathrm{~Hz}, 1 \mathrm{H}), 6.88-6.79(\mathrm{~m}, 2 \mathrm{H}), 5.99-5.88(\mathrm{~m}, 1 \mathrm{H}), 5.20(\mathrm{dq}, J=17.2,1.7 \mathrm{~Hz}, 1 \mathrm{H}), 5.11$ (dt, $J=10.2,1.5 \mathrm{~Hz}, 1 \mathrm{H}), 3.88(\mathrm{~d}, J=11.0 \mathrm{~Hz}, 6 \mathrm{H}), 3.73(\mathrm{~s}, 2 \mathrm{H}), 3.28(\mathrm{dt}, J=6.0,1.5 \mathrm{~Hz}, 2 \mathrm{H})$. ${ }^{13} \mathrm{C}$ NMR $\left(126 \mathrm{MHz}, \mathrm{CDCl}_{3}\right) \delta 148.96,148.01,136.83,132.95,120.25,115.99,111.41,111.00$, 55.91, 53.09, 51.77. HRMS (DART) $\mathrm{m} / \mathrm{z}$ calculated for $\mathrm{C}_{12} \mathrm{H}_{18} \mathrm{NO}_{2}(\mathrm{M}+\mathrm{H})^{+} 208.13375$, found 208.13383 (error $0.37 \mathrm{ppm}$ ).

Synthesis of 2-(2-Ethoxyethoxy)ethane thiol (EEET). The synthesis of 2-(2-ethoxyethoxy)ethane1-thiol was adapted from a literature procedure ${ }^{1}$. 2-(2-(2-Bromoethoxy)ethoxy)ethane (2.62 g, $13.3 \mathrm{mmol}, 1.0$ equiv.) and thiourea (1.52 g, $20.0 \mathrm{mmol}, 0.67$ equiv.) were refluxed in $50 \mathrm{~mL}$ of water under $\mathrm{N}_{2}$ for $18 \mathrm{~h}$. A solution of $4 \mathrm{~g}$ of $\mathrm{NaOH}$ in $10 \mathrm{~mL}$ of water, sparged for 5 min with $\mathrm{N}_{2}$, was added to the reaction mixture at room temperature and then the reaction was refluxed for an additional $3 \mathrm{~h}$. Upon cooling to room temperature, the reaction mixture was poured into icecold water under rapid stirring and the $\mathrm{pH}$ of the solution was adjusted to $\mathrm{pH}=4$ with concentrated $\mathrm{HCl}$. The reaction mixture was extracted with DCM $(3 \times 50 \mathrm{~mL})$ and the combined organic layers dried over $\mathrm{Na}_{2} \mathrm{SO}_{4}$. The product was obtained as a clear oil after rotary evaporation (1.6 g, 80\% yield). ${ }^{1} \mathrm{H}$ NMR $\left(500 \mathrm{MHz}, \mathrm{CDCl}_{3}\right) \delta 3.64-3.55(\mathrm{~m}, 6 \mathrm{H}), 3.52(\mathrm{q}, J=$ $7.0 \mathrm{~Hz}, 2 \mathrm{H}), 2.69(\mathrm{dt}, J=8.3,6.5 \mathrm{~Hz}, 2 \mathrm{H}), 1.57(\mathrm{t}, J=8.2 \mathrm{~Hz}, 1 \mathrm{H}), 1.20(\mathrm{t}, J=7.0 \mathrm{~Hz}, 3 \mathrm{H}) .13 \mathrm{C}$ NMR $\left(126 \mathrm{MHz}, \mathrm{CDCl}_{3}\right) \delta 73.04,70.42,69.85,66.80,24.33,15.26$. HRMS (DART) m/z calculated for $\mathrm{C}_{6} \mathrm{H}_{15} \mathrm{O}_{2} \mathrm{~S}(\mathrm{M}+\mathrm{H})^{+}$151.07928, found 151.07919 (error $0.60 \mathrm{ppm}$ ).

Film Preparation. Cross-linked networks were prepared by combining oligomer (30 mg, 21.8 $\mu \mathrm{mol}$ ), 2,2'-(ethylenedioxy)diethanethiol (EDET, $7.15 \mathrm{mg}, 39.3 \mu \mathrm{mol}$ ) or ethylene glycol bismercaptoacetate (EBMA, $8.26 \mathrm{mg}, 39.3 \mu \mathrm{mol}$ ), and 2,2-dimethoxy-2-phenylacetophenone (DMPA) photoinitiator $(1.11 \mathrm{mg}, 4.4 \mu \mathrm{mol})$. Acetonitrile (final [oligomer] $=720 \mathrm{mM}$ ) was added to dissolve the solids and the solution was transferred to a PTFE mold with wells of 100 $\mathrm{mm}(\mathrm{d}) \times 1 \mathrm{~mm}(\mathrm{~h})$. The solution was irradiated with UV-light $\left(20 \mathrm{~mW} / \mathrm{cm}^{2}\right)$ for 20, 30, and 60 min for gel-fraction analysis. Films for mechanical characterization by DMTA were prepared in a similar fashion: oligomer $(270 \mathrm{mg}, 196.3 \mu \mathrm{mol})$, EDET $(64.4 \mathrm{mg}, 353.3 \mu \mathrm{mol})$ or EBMA (74 $\mathrm{mg}, 353.3 \mu \mathrm{mol})$, and DMPA $(10.1 \mathrm{mg}, 39.3 \mu \mathrm{mol}$, [oligomer] $=720 \mathrm{mM}$ in acetonitrile) were mixed and irradiated with UV-light for $60 \mathrm{~min}$ in a PTFE mold with larger wells [250 mm (d) x $1 \mathrm{~mm}(\mathrm{~h})]$. After curing, each film was removed from the mold, swelled in acetonitrile $(1 \mathrm{~mL}$ for $30 \mathrm{mg}$ scale, $10 \mathrm{~mL}$ for $270 \mathrm{mg}$ scale) for $48 \mathrm{~h}$. The films were then removed from solvent and dried in vacuo for $14-16 \mathrm{~h}$ at $100^{\circ} \mathrm{C}$ to ensure complete solvent removal. Control networks 
comprising a 1:1:1 molar ratio of mAmAmA, AAmmmA, and AAAmmm (mixed sequence) were prepared on both $30 \mathrm{mg}$ and $300 \mathrm{mg}$ total oligomer scales by the same method. Films for DMTA experiments were cut into tensile bars [ca. $0.7 \mathrm{~mm}(\mathrm{~T}) \times 3 \mathrm{~mm}(\mathrm{~W}) \times 20 \mathrm{~mm}(\mathrm{~L})]$ after swelling and before complete solvent removal. The bars were then placed in an oven at $100^{\circ} \mathrm{C}$ sandwiched between two PTFE sheets and aluminum foil under a $500 \mathrm{~g}$ weight for $14-16 \mathrm{~h}$ post-cure to remove any residual solvent. Upon removal from the oven, the weight was replaced with a room temperature petri dish to maintain the samples' flatness while cooling.

Model thiol-ene kinetics. To investigate the kinetics of the thiol-ene reaction for each allyl functional SD-PU oligomer outside of the cross-linking reactions described below, EEET, a monothiol, was reacted with each oligomer under similar conditions to cross-linking (20 mol\% excess thiol, $20 \mathrm{~mol} \%$ DMPA, [oligomer] $=720 \mathrm{mM}$ in acetonitrile). The conversion of each reaction was determined at $0,1,3,5,10$, and $15 \mathrm{~min}$ by monitoring the disappearance of the oligomer allyl peaks centered at 5.23 and $5.86 \mathrm{ppm}$ with respect to unchanging oligomer methyl peaks centered at $3.02 \mathrm{ppm}$ via ${ }^{1} \mathrm{H}$ NMR spectroscopy.

Gel fraction analysis. Network conversion was monitored by NMR and fluorescence spectroscopy. Each film was prepared as described in the film preparation section. At a given time point, the three SD-PUM films were irradiated simultaneously using a multi-well PTFE mold where each well had a depth of $1 \mathrm{~mm}$ and a diameter of $10 \mathrm{~mm}$. Films were irradiated for 20, 30, and $60 \mathrm{~min}$. Each film was placed in a vial and swelled with $1 \mathrm{~mL}$ of acetonitrile. After $48 \mathrm{~h}$, the sol-fraction was removed, and the solvent was removed under vacuum. The mass of the sol fraction was subtracted from the total mass of all starting materials to determine the gel fraction by mass. In this case, cross-linker, photoinitiator, and oligomer contribute to sol and gel fraction. Following gravimetric analysis, the sol fraction was re-dissolved in $1 \mathrm{~mL}$ of acetonitrile and analyzed by fluorescence spectroscopy using an excitation wavelength of $270 \mathrm{~nm}$ and recording the fluorescence intensity at maximum emission $(306 \mathrm{~nm})$. The amount of oligomer extracted from each network was determined by interpolating the unknown oligomer concentrations from standard curves of each oligomer. The gel fraction was obtained by subtracting the sol fraction from the total SD-PUM added to the film.

Degradation of EBMA networks for conversion analysis. After swelling and drying, EBMA (30 $\mathrm{mg}$ ) films were cut in half and one portion was placed in a solution containing $300 \mu \mathrm{L}$ of trifluoroacetic acid, $300 \mu \mathrm{L}$ of water, and $300 \mu \mathrm{L}$ of acetonitrile and heated to $40^{\circ} \mathrm{C}$ for $12 \mathrm{~h}$ to achieve complete network degradation via ester hydrolysis. After degradation, the solution was analyzed via LC-MS to identify the degraded components.

(1) Zhu, J.; Waengler, C.; Lennox, R. B.; Schirrmacher, R. Preparation of Water-Soluble Maleimide-Functionalized $3 \mathrm{Nm}$ Gold Nanoparticles: A New Bioconjugation Template.

Langmuir 2012, 28 (13), 5508-5512. 
Supplementary Table 1. Expected and observed masses via LC-MS for each step in SD-PU oligomer synthesis.

\begin{tabular}{|c|c|c|c|c|c|c|c|c|}
\hline mAmAmA & Exp. & Obs. & \multirow[t]{2}{*}{ AAmmmA } & Exp. & Obs. & \multirow[t]{2}{*}{ AAAmmm } & Exp. & Obs. \\
\hline & \multicolumn{2}{|c|}{$[\mathrm{M}+\mathrm{H}]^{+}$} & & \multicolumn{2}{|l|}{$[\mathrm{M}+\mathrm{H}]^{+}$} & & \multicolumn{2}{|l|}{$[\mathrm{M}+\mathrm{H}]^{+}$} \\
\hline $1 \mathrm{mer}$ & $181.1^{\mathrm{a}}$ & $181.1^{\mathrm{a}}$ & $1 \mathrm{mer}$ & 208.1 & $208.1^{b}$ & $1 \mathrm{mer}$ & 208.1 & $208.1^{\mathrm{b}}$ \\
\hline $2 \mathrm{mer}$ & 360.1 & 360.0 & $2 \mathrm{mer}$ & 386.2 & 386.1 & $2 \mathrm{mer}$ & 386.2 & 386.1 \\
\hline $3 \mathrm{mer}$ & 401.2 & 401.1 & 3 mer & 427.2 & 427.3 & $3 \mathrm{mer}$ & 427.2 & 427.3 \\
\hline $4 \mathrm{mer}$ & 579.2 & 579.3 & 4 mer & 605.2 & 605.1 & 4 mer & 605.2 & 605.1 \\
\hline $5 \mathrm{mer}$ & 594.3 & 594.1 & $5 \mathrm{mer}$ & 620.3 & 620.1 & $5 \mathrm{mer}$ & 645.3 & 646.2 \\
\hline $6 \mathrm{mer}$ & 772.3 & 772.3 & $6 \mathrm{mer}$ & 798.4 & 798.1 & $6 \mathrm{mer}$ & 824.3 & 824.3 \\
\hline $7 \mathrm{mer}$ & 813.4 & 813.2 & $7 \mathrm{mer}$ & 813.4 & 813.2 & $7 \mathrm{mer}$ & 839.4 & 839.2 \\
\hline 8 mer & 991.4 & 991.2 & 8 mer & 991.4 & 991.4 & 8 mer & $1034.4^{\mathrm{c}}$ & $1034.4^{\mathrm{c}}$ \\
\hline 9mer & 1006.4 & 1006.3 & 9mer & 1006.4 & 1006.3 & 9mer & 1032.5 & 1032.3 \\
\hline $10 \mathrm{mer}$ & 1184.5 & 1184.4 & $10 \mathrm{mer}$ & $1201.5^{c}$ & $1201.3^{c}$ & $10 \mathrm{mer}$ & $1227.5^{c}$ & $1227.3^{c}$ \\
\hline $11 \mathrm{mer}$ & 1225.5 & 1225.5 & $11 \mathrm{mer}$ & 1225.5 & 1225.2 & $11 \mathrm{mer}$ & 1225.5 & 1225.3 \\
\hline $12 \mathrm{mer}$ & 1375.6 & 1375.5 & $12 \mathrm{mer}$ & 1375.6 & 1375.3 & $12 \mathrm{mer}$ & 1375.6 & 1375.4 \\
\hline
\end{tabular}

${ }^{a}$ Expected and observed masses are for the radical cation $(\mathrm{M})^{+}$and observed mass was measured with HRMS (DART). ${ }^{b}$ Observed mass measured with HRMS (DART). ${ }^{c}$ Expected and observed masses are for $\left[\mathrm{M}+\mathrm{H}_{2} \mathrm{O}\right]^{+}$.

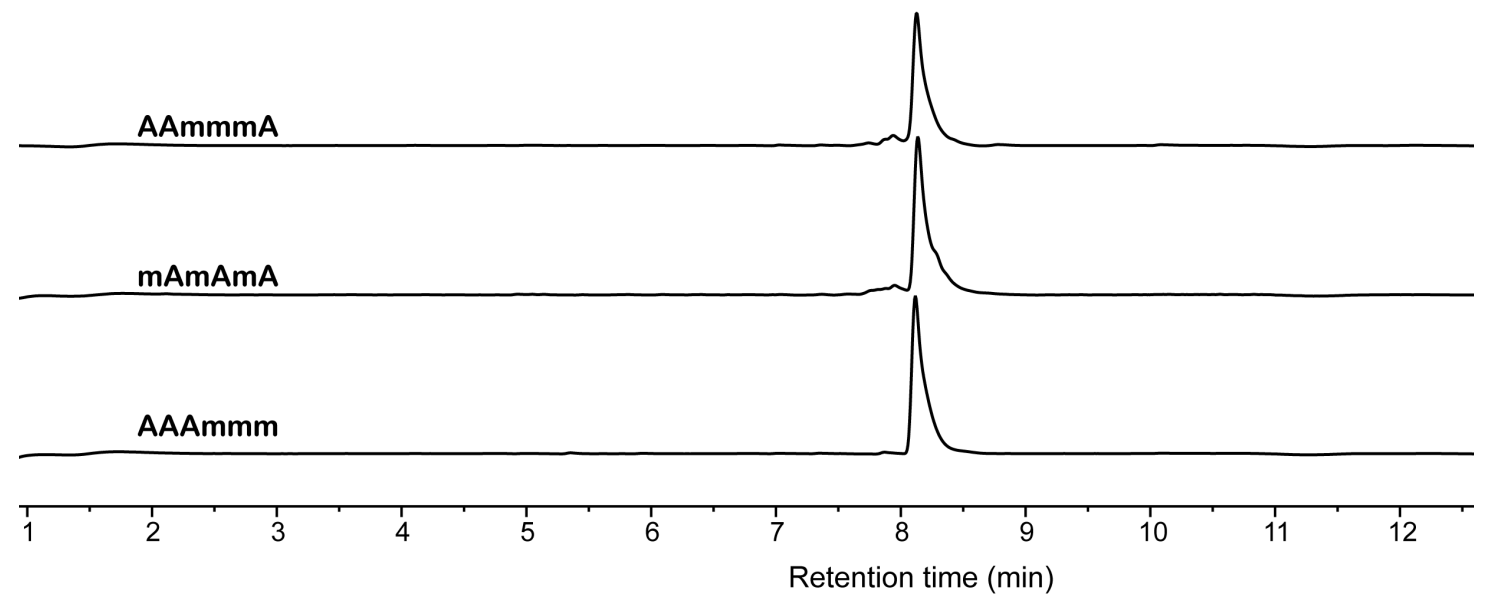

Supplementary Figure 1. Absorbance spectra of each SD-PUM at $260 \mathrm{~nm}$ obtained during LCMS analysis (Figure 1C with expanded baseline). 


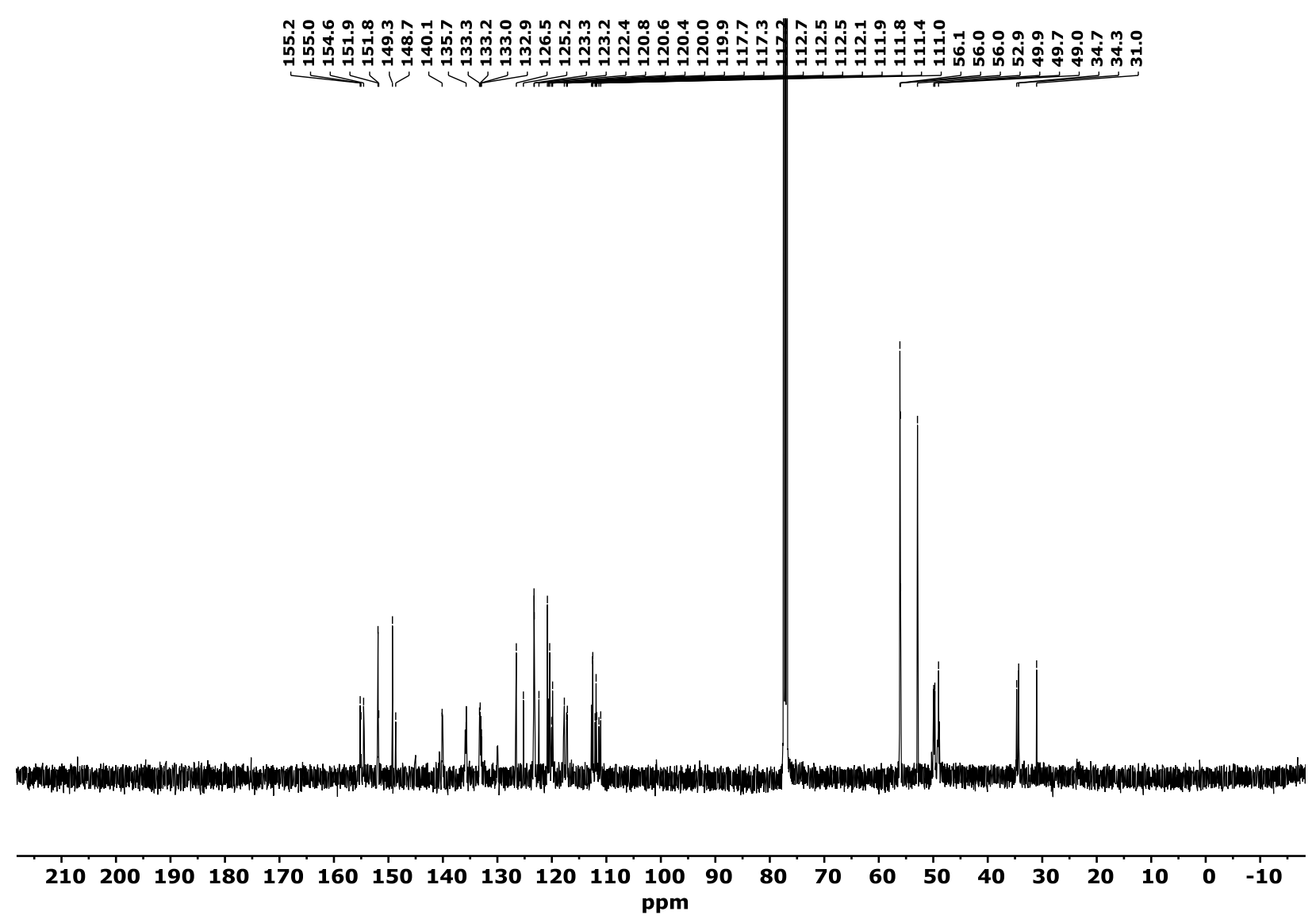

Supplementary Figure 2. ${ }^{13} \mathrm{C}$ NMR spectrum of AAmmmA in $\mathrm{CDCl}_{3}$. 


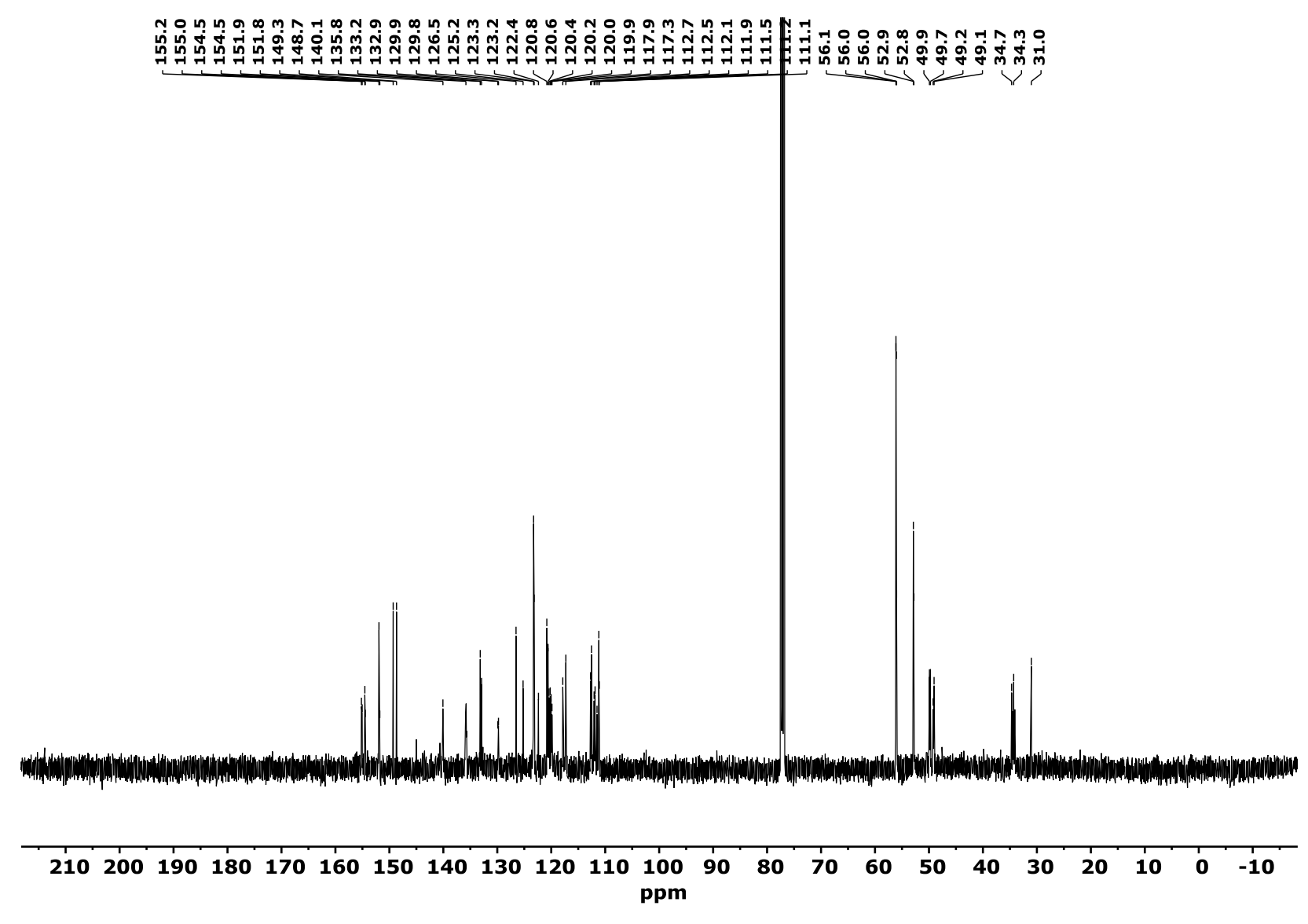

Supplementary Figure 3. ${ }^{13} \mathrm{C}$ NMR spectrum of mAmAmA in $\mathrm{CDCl}_{3}$. 


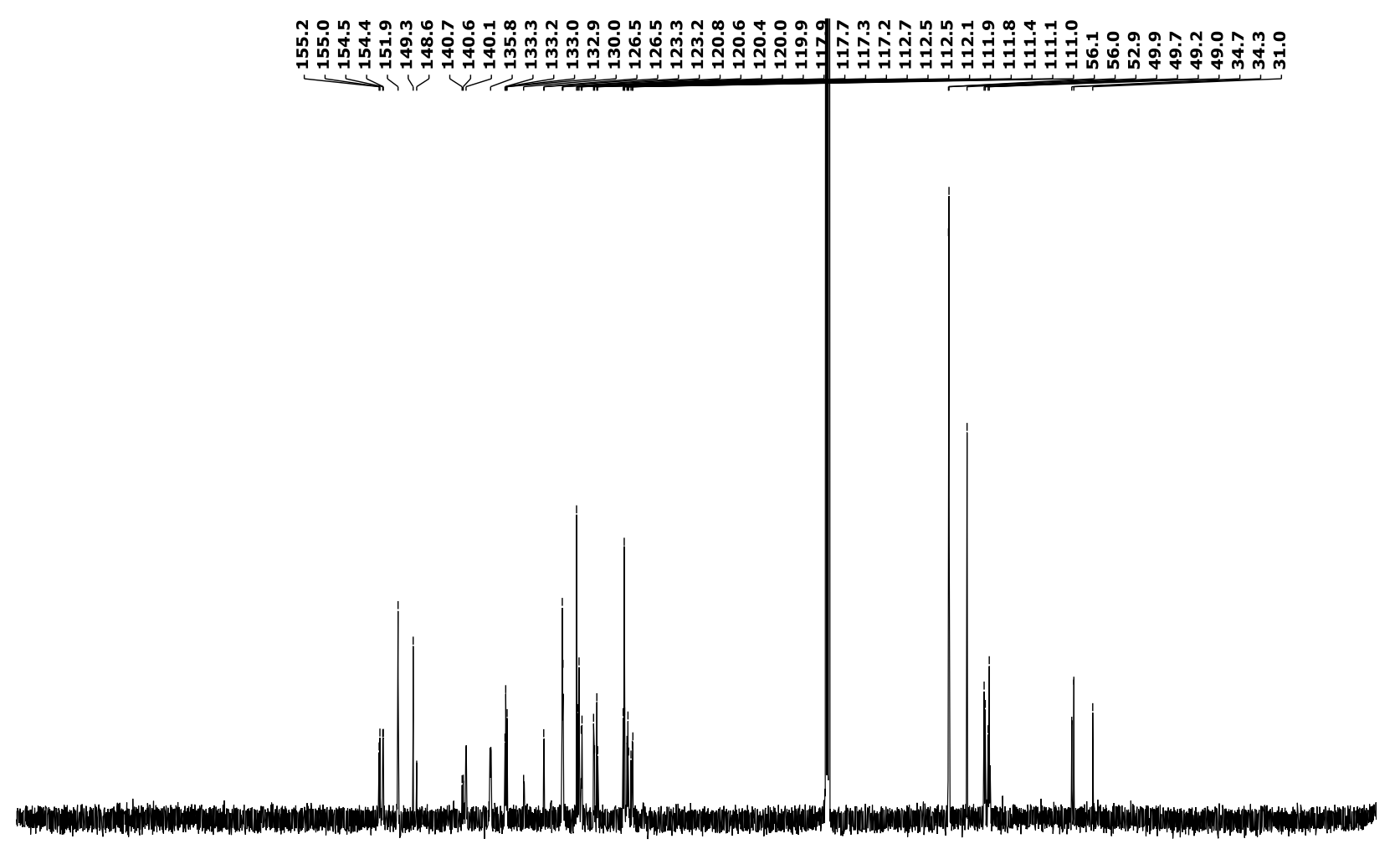

\section{$\begin{array}{lllllllllllllllllllllll}210 & 200 & 190 & 180 & 170 & 160 & 150 & 140 & 130 & 120 & 110 & 100 & 90 & 80 & 70 & 60 & 50 & 40 & 30 & 20 & 10 & 0 & -10\end{array}$}

Supplementary Figure 4. ${ }^{13} \mathrm{C}$ NMR spectrum of AAAmmm in $\mathrm{CDCl}_{3}$.

Supplementary Equation 1. Eyring equation used to calculate Gibbs free energies of activation $\left(\Delta \mathrm{G}^{\dagger}\right)$.

$$
\Delta G^{\ddagger}=-R T \ln \left(\frac{k h}{k_{b}}\right)
$$

$\mathrm{R}$ is the gas constant, $\mathrm{T}$ is absolute temperature, $\mathrm{k}$ is the rate constant, $\mathrm{h}$ is Plank's constant, and $\mathrm{k}_{\mathrm{b}}$ is Boltzmann's constant. 


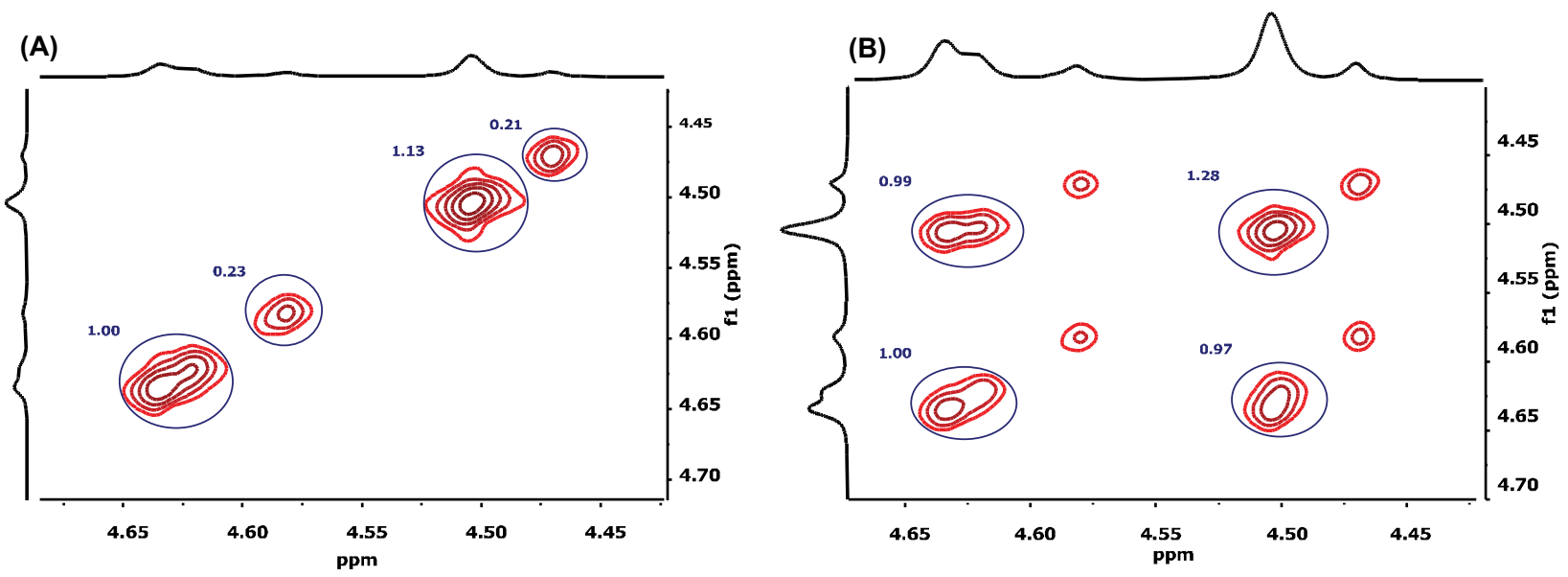

Supplementary Figure 5. ROESY 2D ${ }^{1} \mathrm{H}$ NMR spectra of AAmmmA at (A) $0 \mathrm{~ms}$ and (B) 200 ms mixing times in $\mathrm{CDCl}_{3}$.
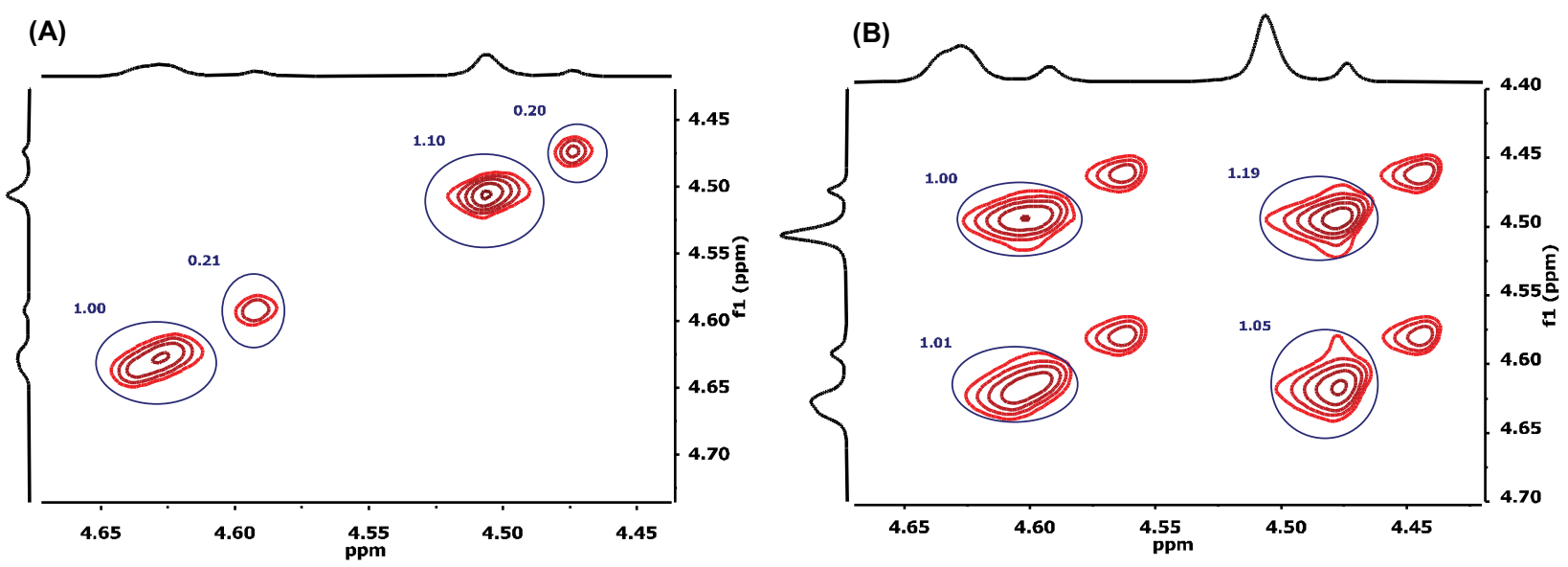

Supplementary Figure 6. ROESY 2D ${ }^{1} \mathrm{H}$ NMR spectra of mAmAmA at (A) $0 \mathrm{~ms}$ and (B) 200 ms mixing times in $\mathrm{CDCl}_{3}$.
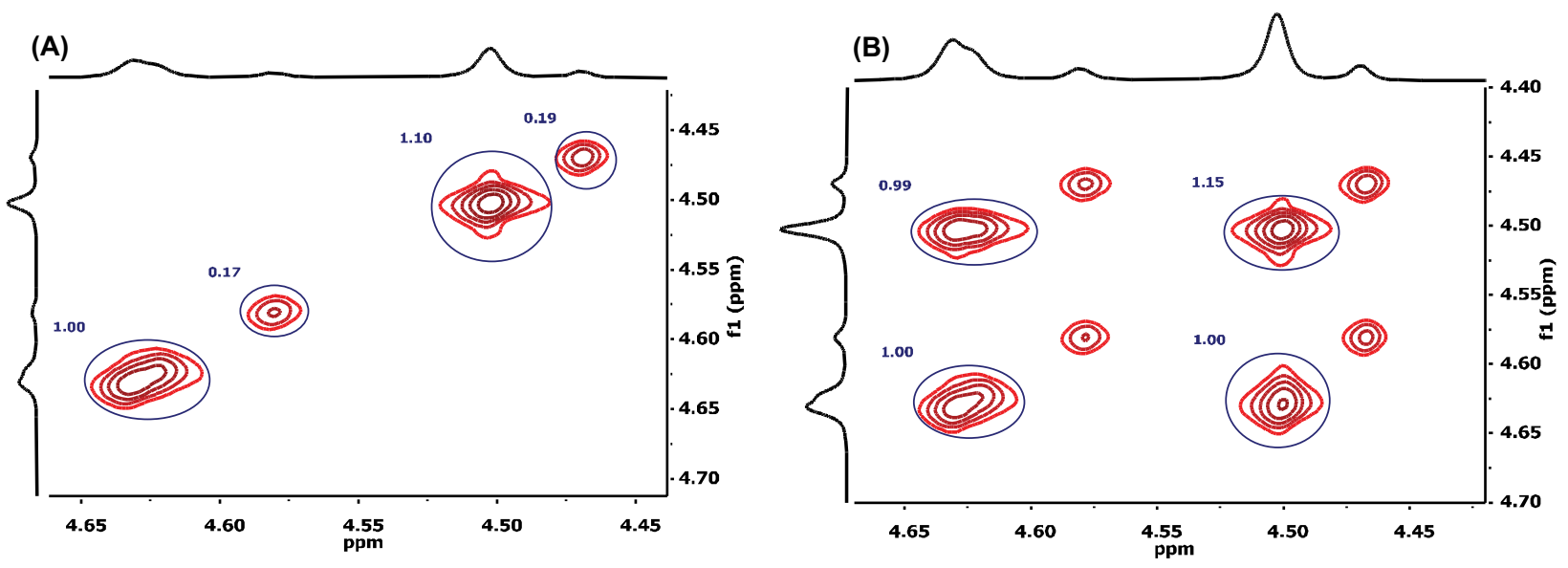

Supplementary Figure 7. ROESY 2D ${ }^{1} \mathrm{H}$ NMR spectra of AAAmmm at (A) $0 \mathrm{~ms}$ and (B) 200 ms mixing times in $\mathrm{CDCl}_{3}$. 


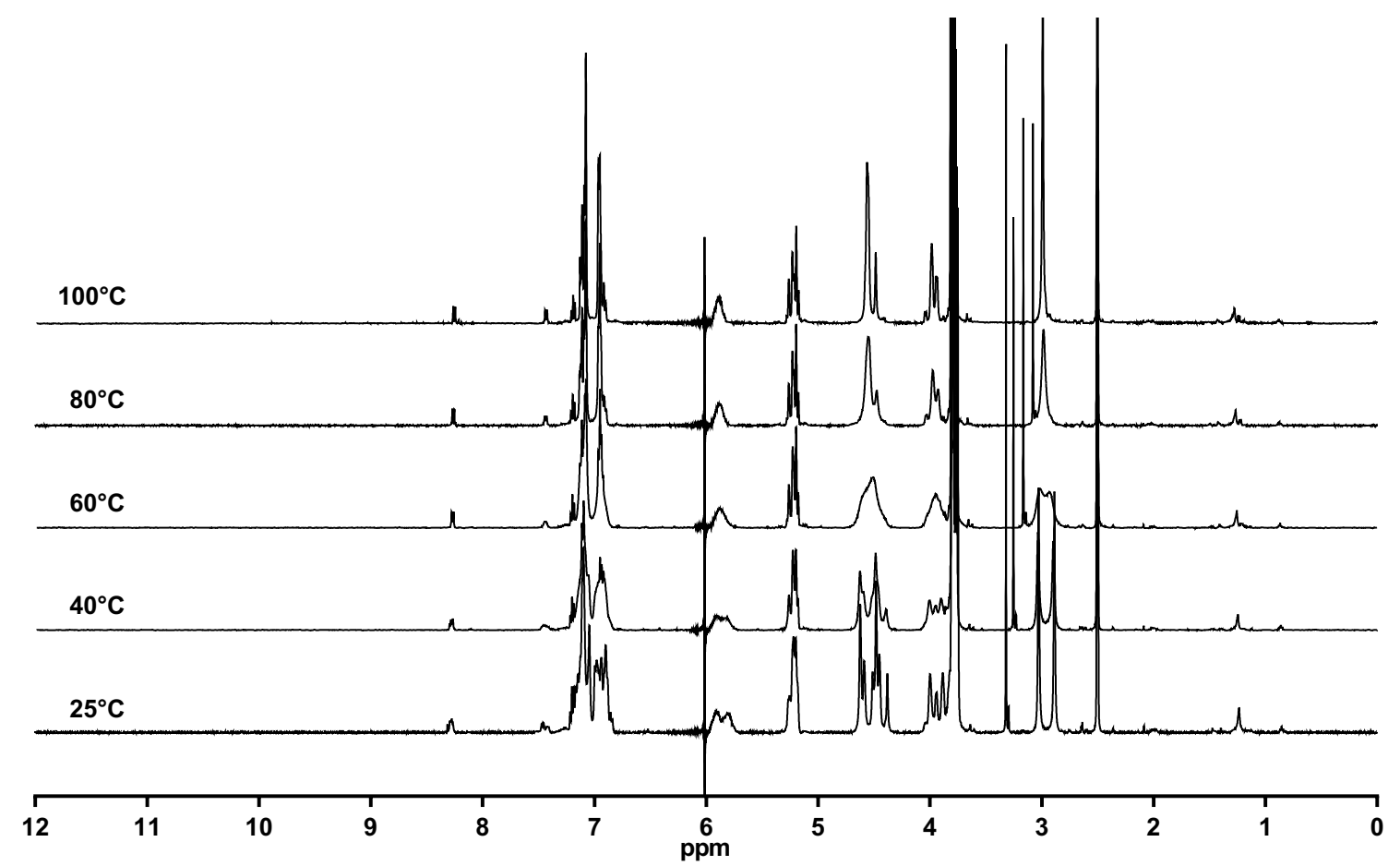

Supplementary Figure 8. Variable temperature ${ }^{1} \mathrm{H}$ NMR spectra of AAmmmA in DMSO-d 6 .

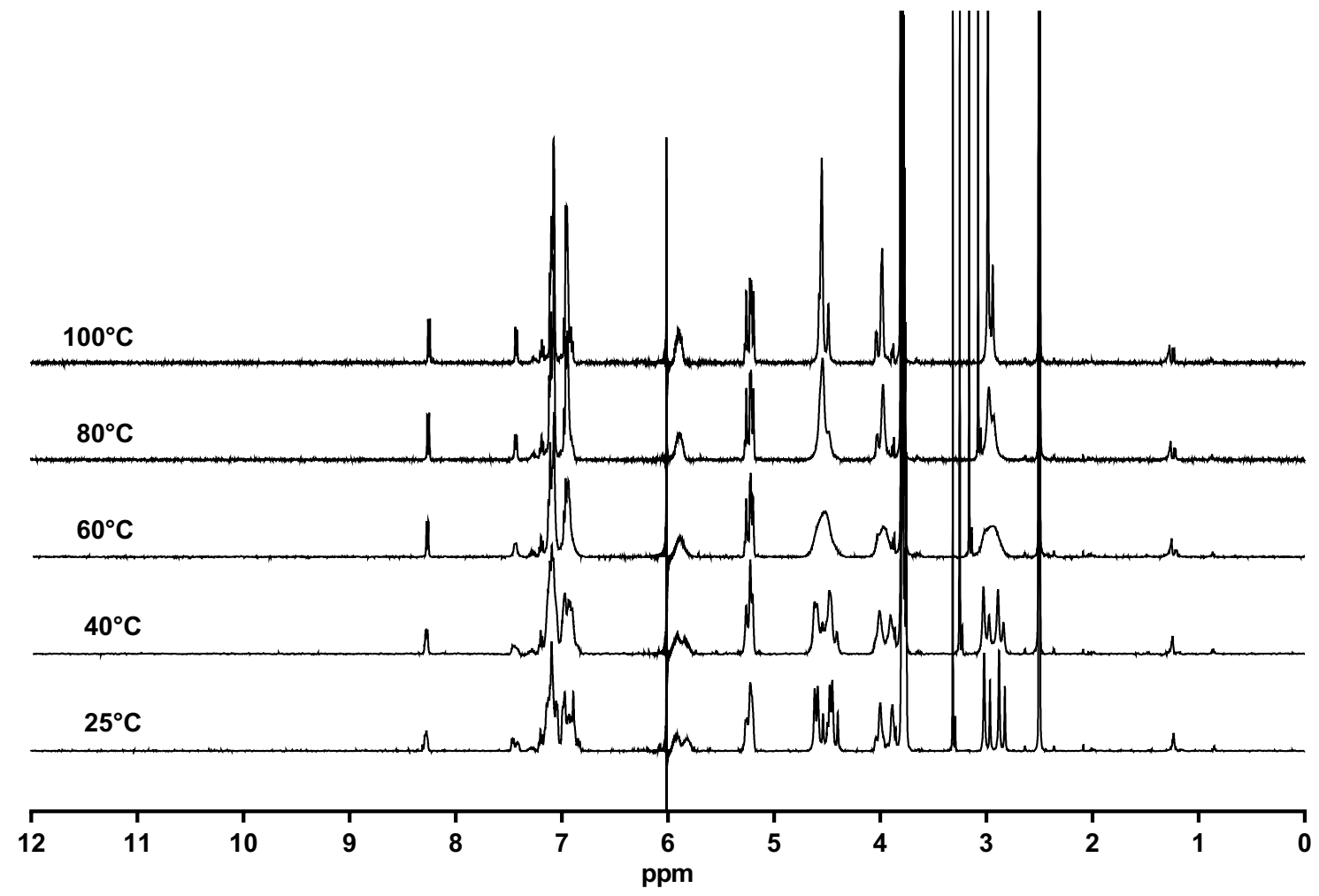

Supplementary Figure 9. Variable temperature ${ }^{1} \mathrm{H}$ NMR spectra of mAmAmA in DMSO- $\mathrm{d}_{6}$. 


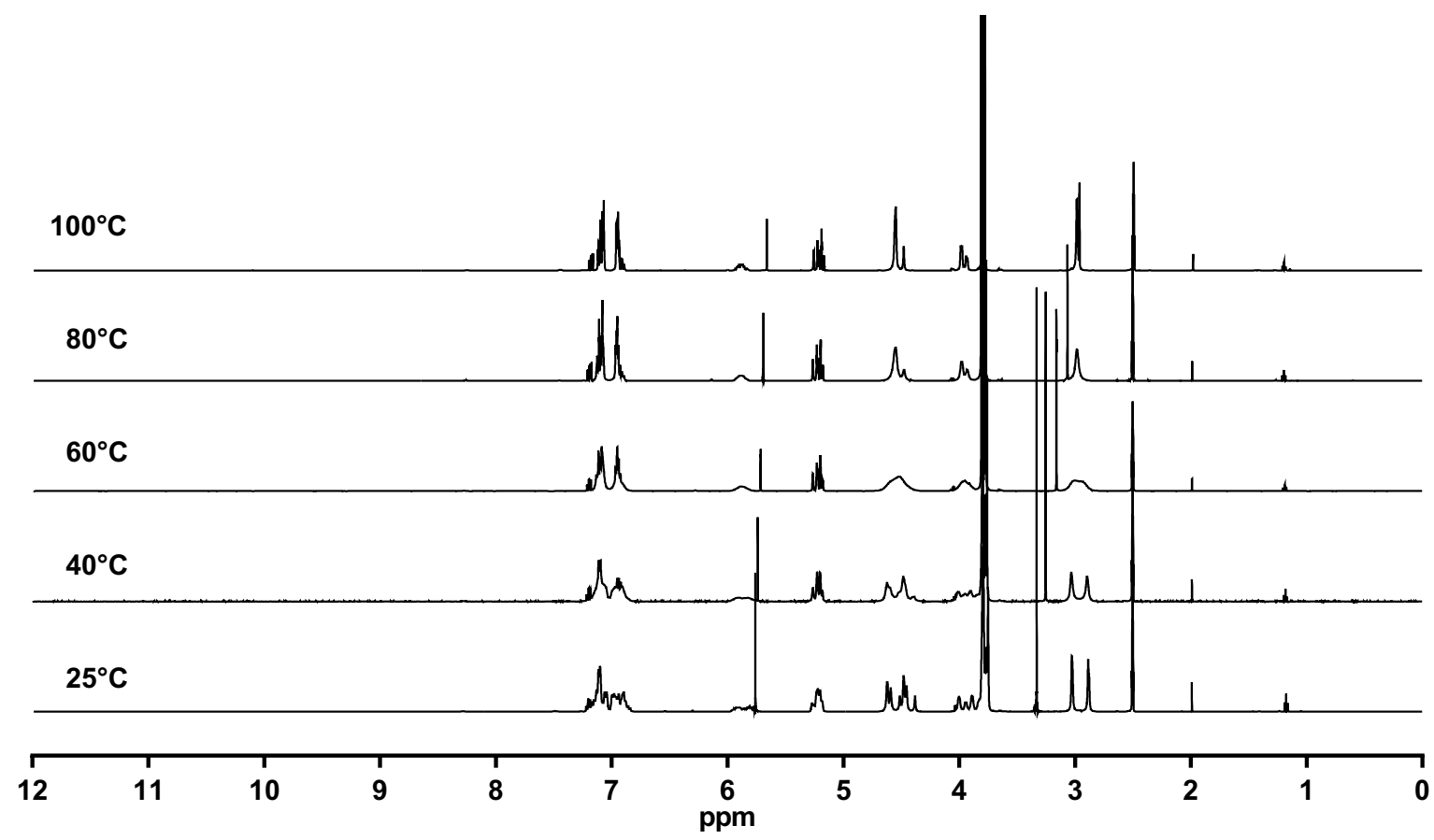

Supplementary Figure 10. Variable temperature ${ }^{1} \mathrm{H}$ NMR spectra of AAAmmm in DMSO-d 6 .

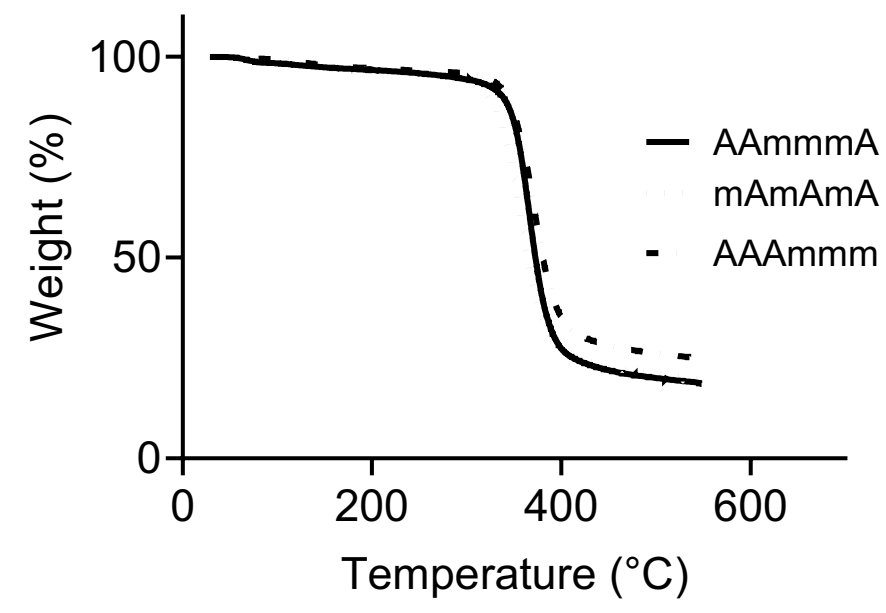

Supplementary Figure 11. Thermograms for each SD-PUM. 


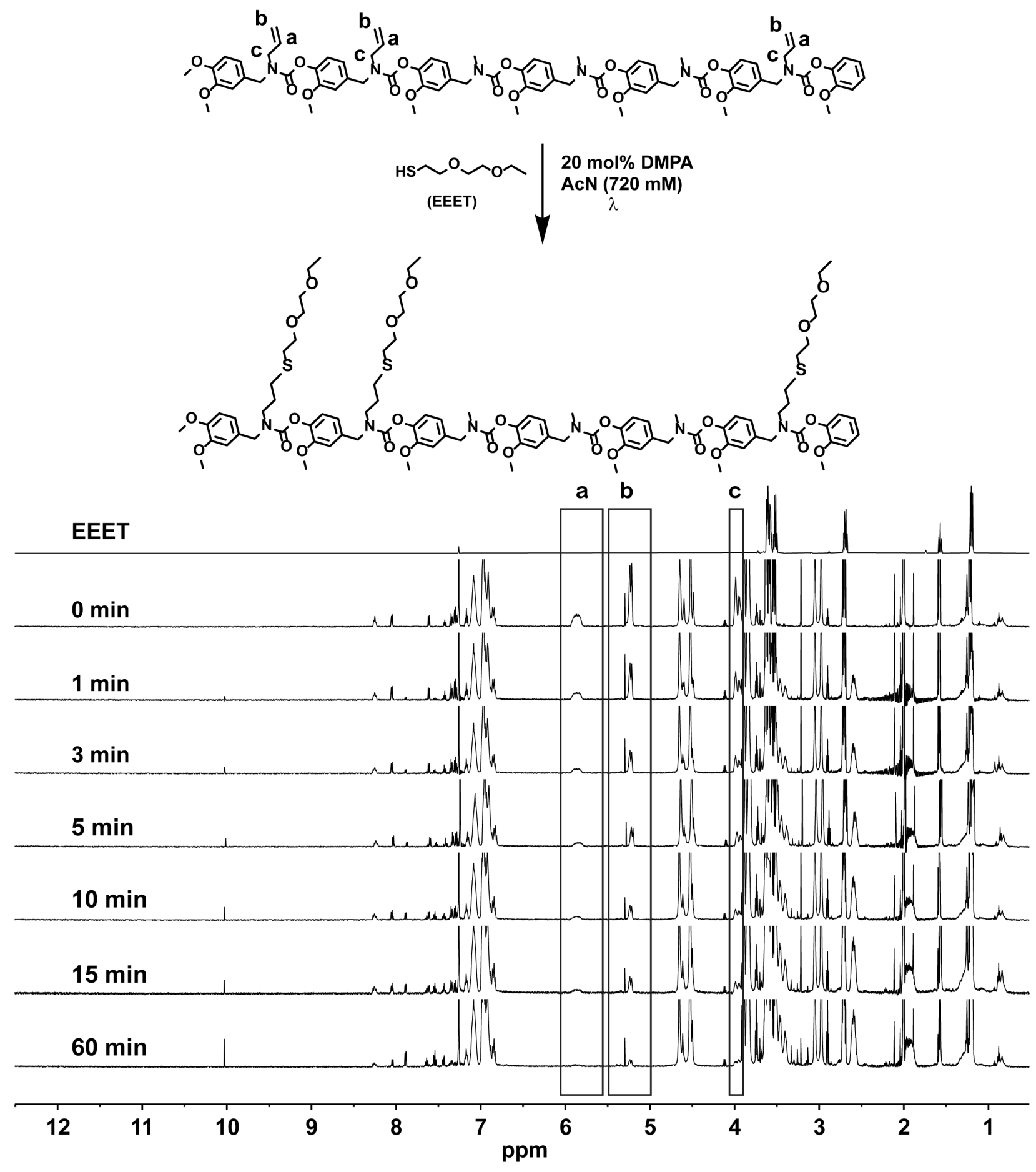

Supplementary Figure 12. ${ }^{1} \mathrm{H}$ NMR spectra for the thiol-ene reaction of AAmmmA with EEET in the presence of DMPA $(20 \mathrm{~mol} \%)$ ([oligomer] $=720 \mathrm{mM}$ in acetonitrile) at $0,1,3,5,10$, and $15 \mathrm{~min}$. Spectra were collected in $\mathrm{CDCl}_{3}$. 

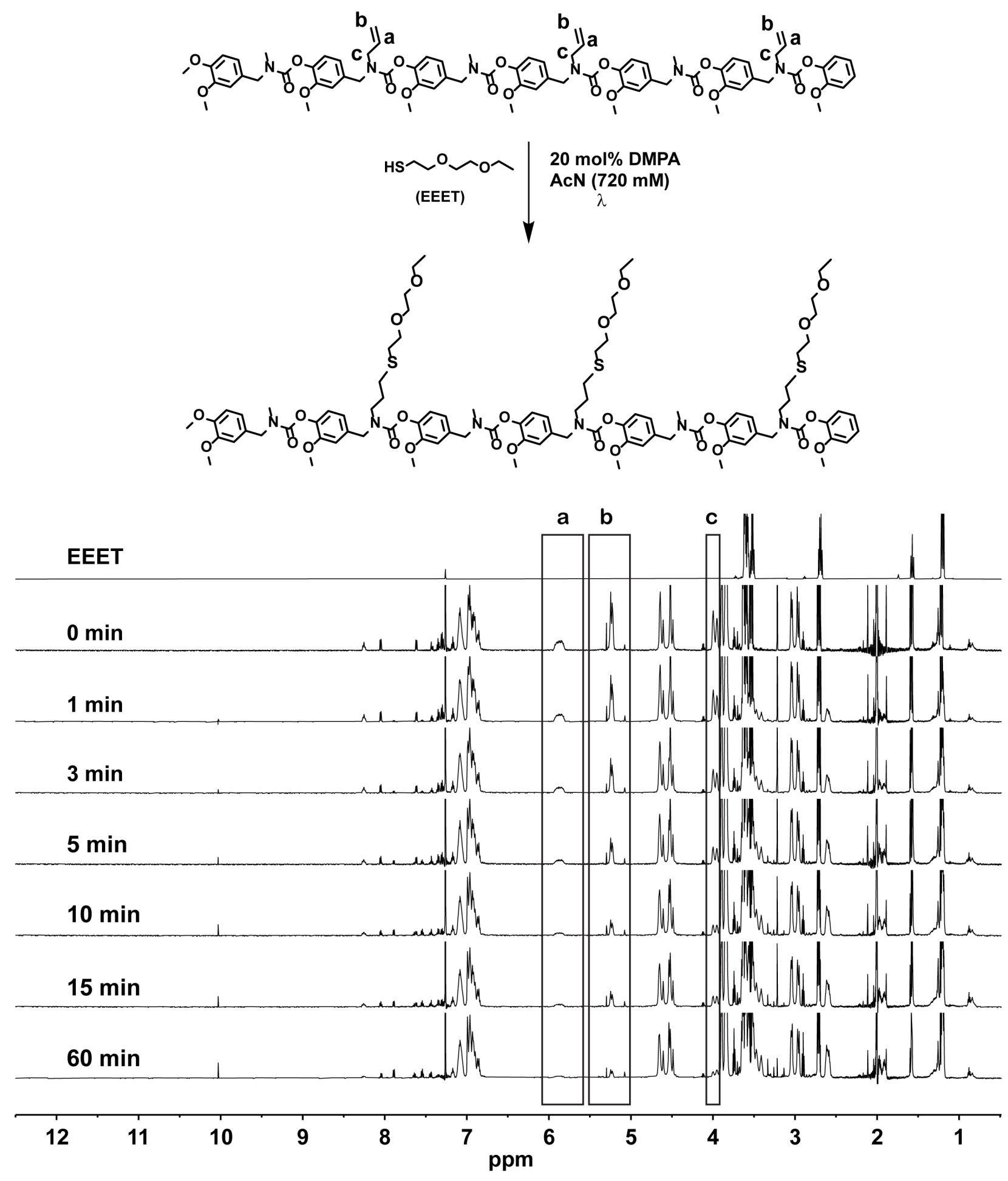

Supplementary Figure 13. ${ }^{1} \mathrm{H}$ NMR spectra for the thiol-ene reaction of $\mathrm{mAmAmA}$ with EEET in the presence of DMPA $(20 \mathrm{~mol} \%)$ ([oligomer] $=720 \mathrm{mM}$ in acetonitrile) at $0,1,3,5,10$, and $15 \mathrm{~min}$. Spectra were collected in $\mathrm{CDCl}_{3}$. 

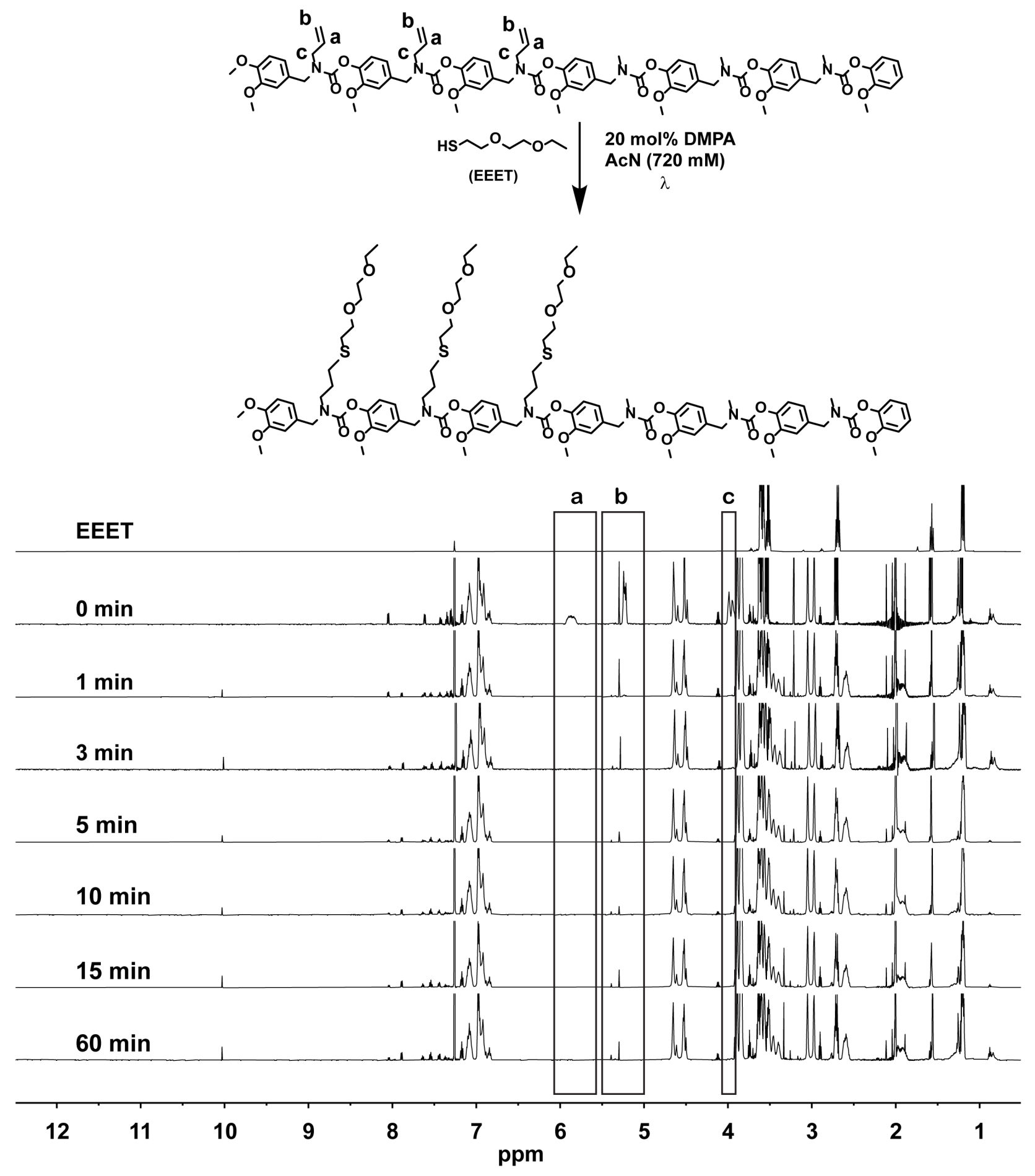

Supplementary Figure 14. ${ }^{1} \mathrm{H}$ NMR spectra for the thiol-ene reaction of AAAmmm with EEET in the presence of DMPA (20 mol\%) ([oligomer] $=720 \mathrm{mM}$ in acetonitrile) at $0,1,3,5,10,15$, and $60 \mathrm{~min}$. Spectra were collected in $\mathrm{CDCl}_{3}$. 


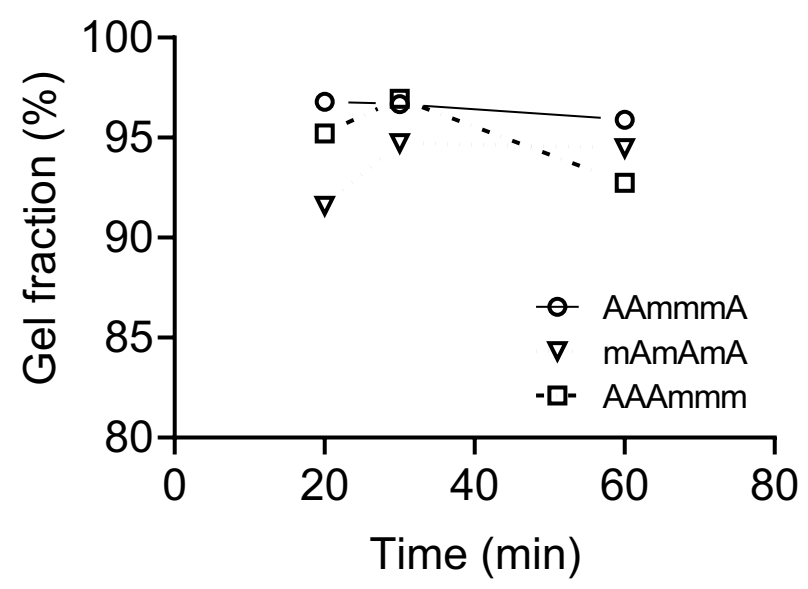

Supplementary Figure 15. Gel fraction analyses (gravimetric) for SD-PUM networks crosslinked with EDET for 20, 30, and 60 min.

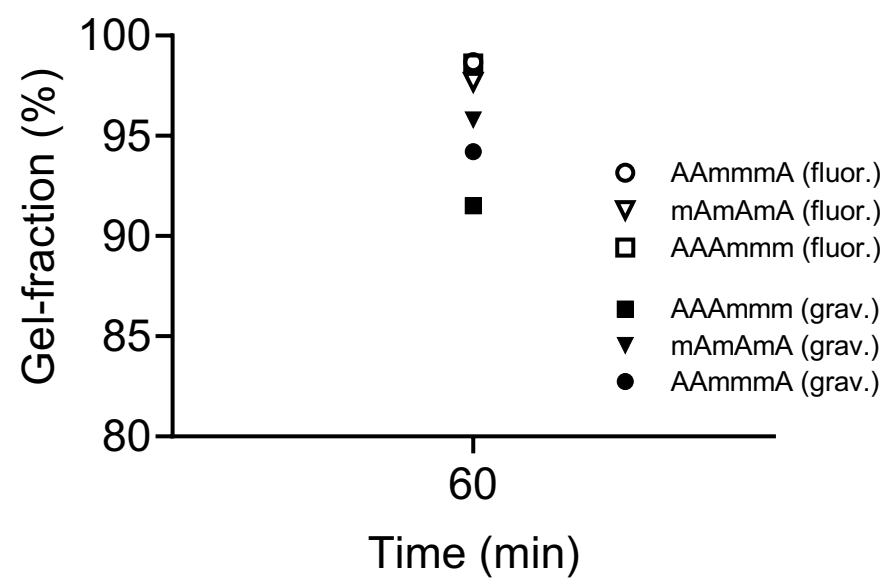

Supplementary Figure 16. Gel fraction analyses (fluorescence-open symbol, gravimetric-closed symbol) for SD-PUM networks cross-linked with EBMA for $60 \mathrm{~min}$. Gel fraction data obtained via fluorescence is a measure of oligomer that was not incorporated in the network and does not take into account thiol-based cross-linkers (reacted or unreacted) or initiator in the sol fraction. 
A

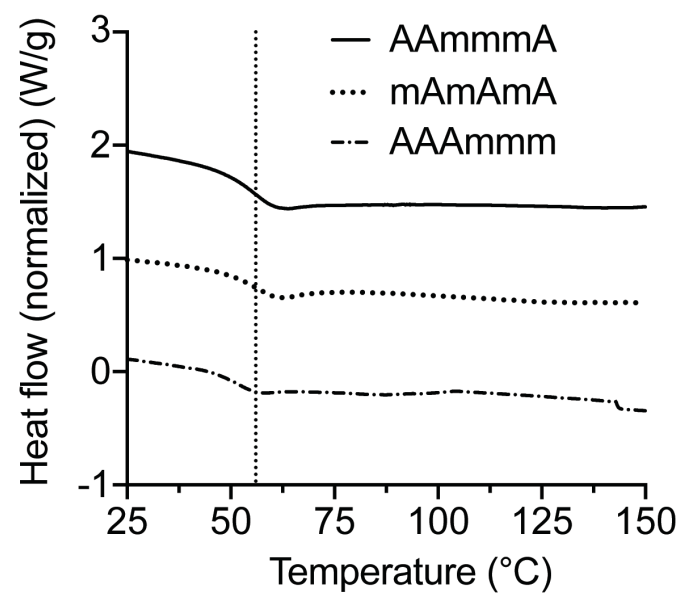

B

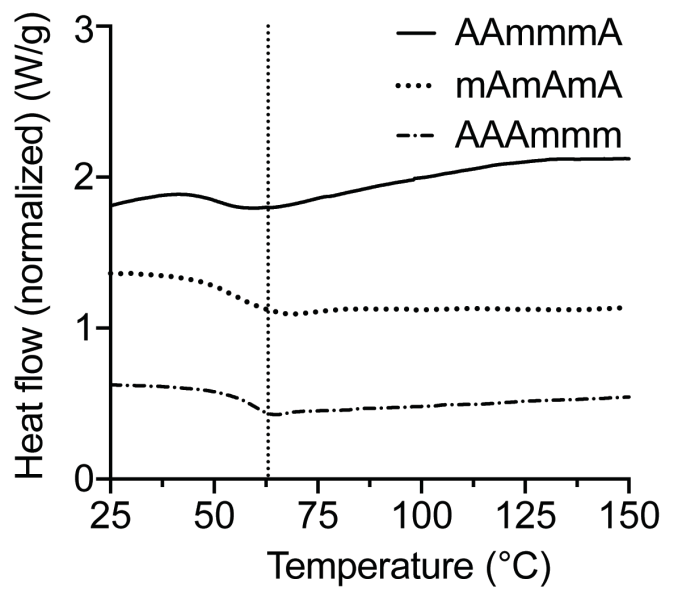

Supplementary Figure 17. DSC of networks formed with EDET (A) or EBMA (B). In (A) and (B), the dotted vertical lines indicate the glass transition temperatures of the AAAmmm networks.

(A)

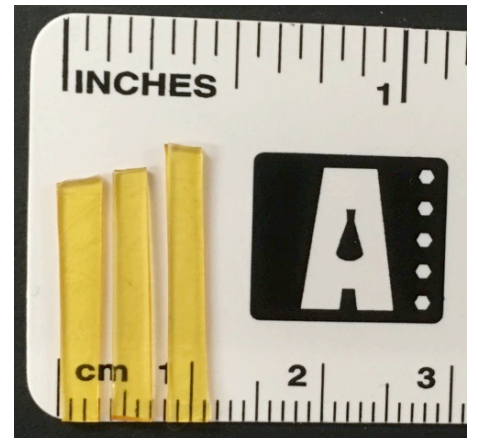

(B)

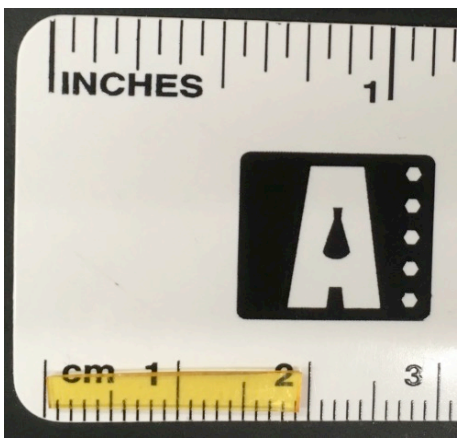

Supplementary Figure 18. Pictures of the mAmAmA-EDET network prepared for rheological testing. 

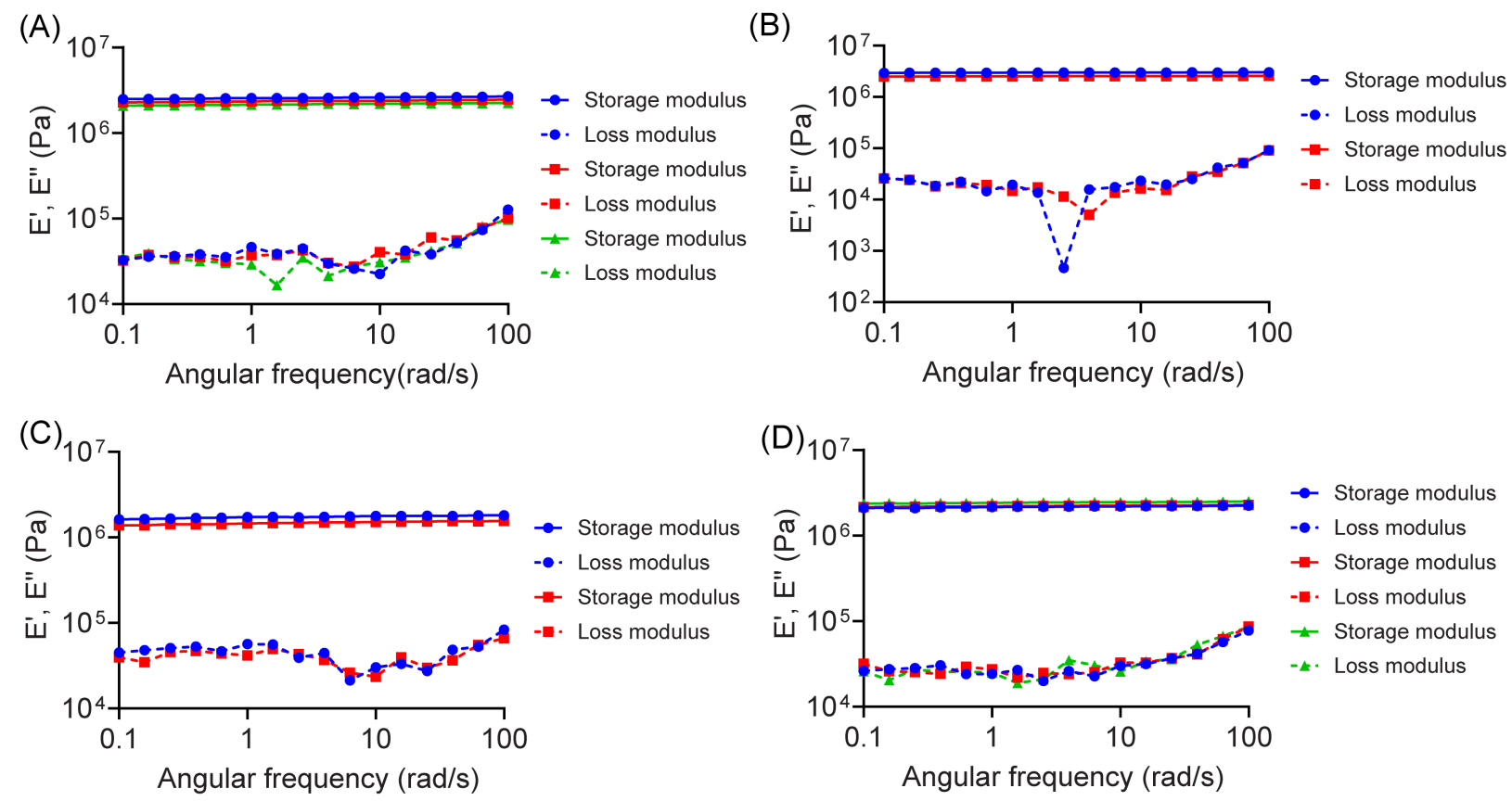

Supplementary Figure 19. Frequency sweeps at $150{ }^{\circ} \mathrm{C}(0.5 \%$ strain $)$ of SD-PUM networks with EDET cross-linker via tensile rheology for each of the networks derived from (A) AAmmmA, (B) mAmAmA, (C) AAAmmm, and (D) a mixed sequence control network (1:1:1 molar ratio of AAmmmA:mAmAmA:AAAmmm); experiments were performed in duplicate or triplicate. 

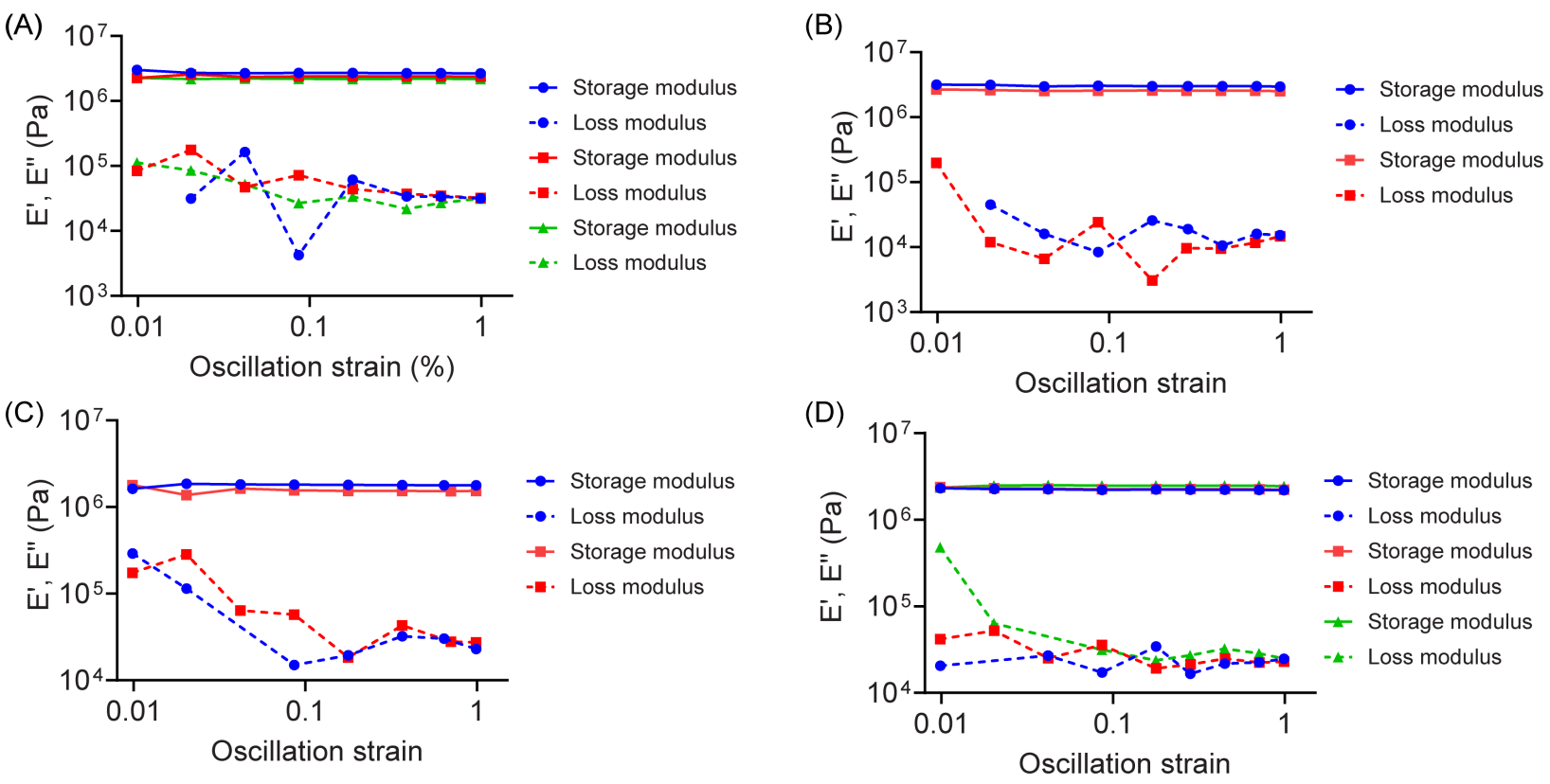

Supplementary Figure 20. Strain sweeps at $150{ }^{\circ} \mathrm{C}\left(6.28 \mathrm{rad} \mathrm{s}^{-1}\right)$ of SD-PUM networks with EDET cross-linker via tensile rheology for each of the networks derived from (A) AAmmmA, (B) mAmAmA, (C) AAAmmm, and (D) a mixed sequence control network (1:1:1 molar ratio of AAmmmA:mAmAmA:AAAmmm); experiments were performed in duplicate or triplicate. 

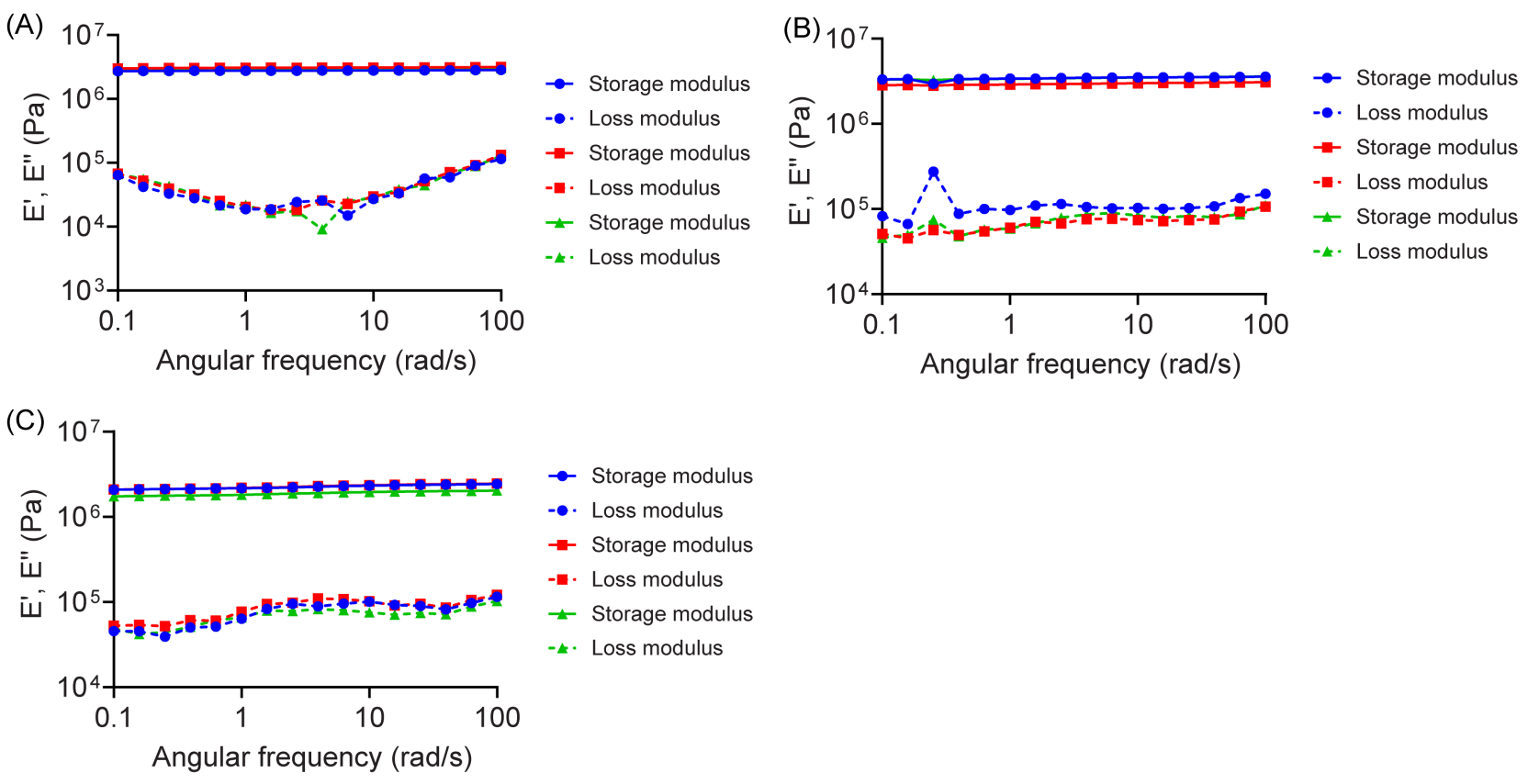

Supplementary Figure 21. Frequency sweeps at $150{ }^{\circ} \mathrm{C}(0.5 \%$ strain $)$ of SD-PUM networks with EBMA cross-linker via tensile rheology for each of the networks derived from (A) AAmmmA, (B) mAmAmA, and (C) AAAmmm; experiments were performed in triplicate. 
(A)

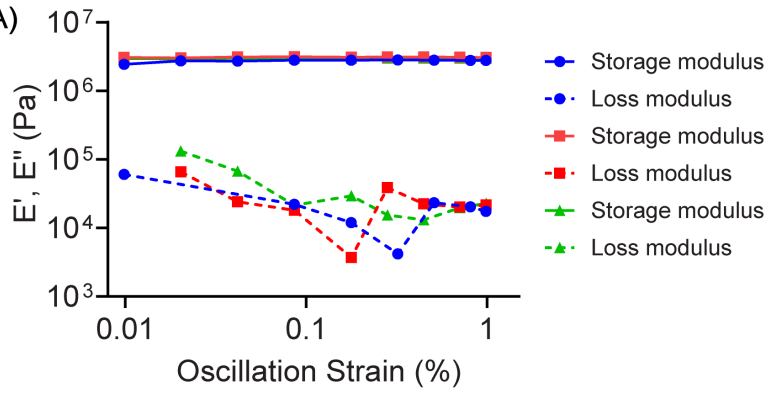

(C)

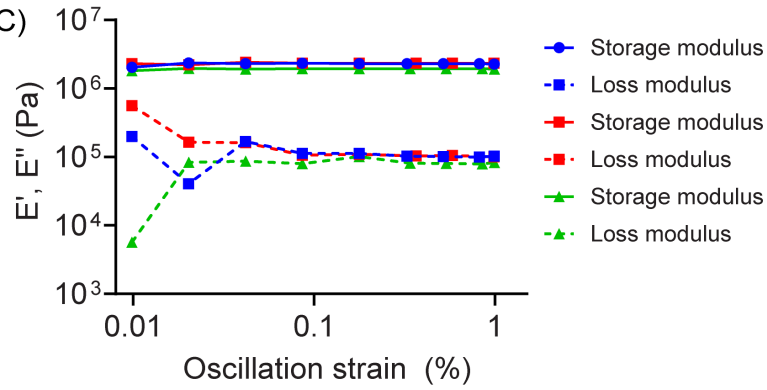

(B)

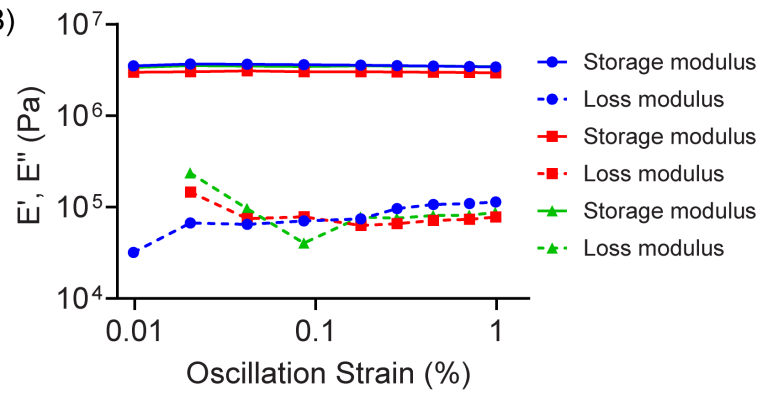

Supplementary Figure 22. Strain sweeps at $150{ }^{\circ} \mathrm{C}\left(6.28 \mathrm{rad} \mathrm{s}^{-1}\right)$ of SD-PUM networks with EBMA cross-linker via tensile rheology for each of the networks derived from (A) AAmmmA, (B) mAmAmA, and (C) AAAmmm; experiments were performed in triplicate.

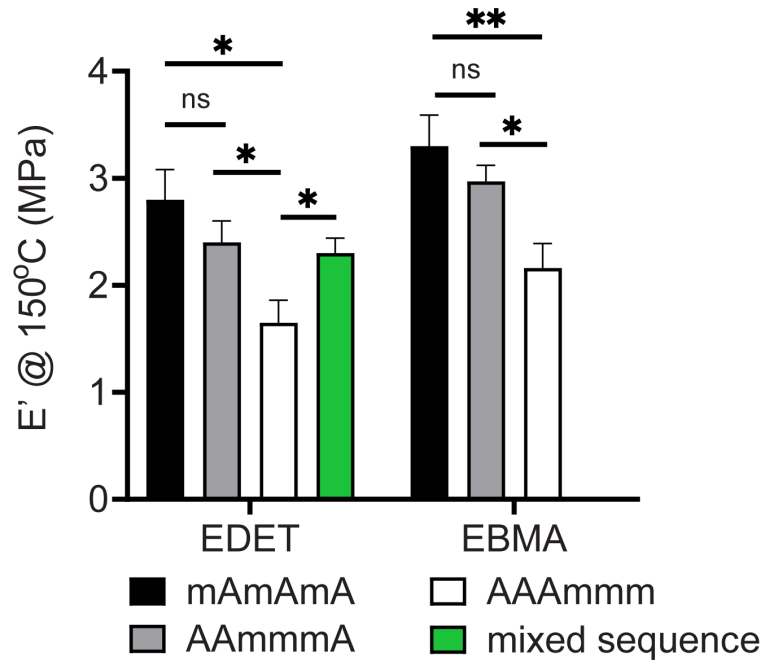

Supplementary Figure 23. Average storage modulus of each SD-PUM-EDET and EBMA network from isothermal frequency sweeps at $150{ }^{\circ} \mathrm{C}$ and plotted here for $6.30 \mathrm{rad} / \mathrm{s}$ (data obtained from 0.1 to $100 \mathrm{rad} / \mathrm{s}$ at a fixed strain of $0.5 \%$ ) with error bars representing the standard deviation from the mean. The trends observed for the storage moduli obtained from frequency sweeps agree with those from temperature sweeps at $150{ }^{\circ} \mathrm{C}$ reported in Figure 5. All measurements were done in triplicate (i.e., measurement on three sample films) except for the mAmAmA-EDET and AAAmmm-EDET networks which were done in duplicates (for duplicates the bars represent a range). ${ }^{*}$, p-value $<0.005,{ }^{*}$, p-value $<0.05$, ns p-value $>0.05$. 

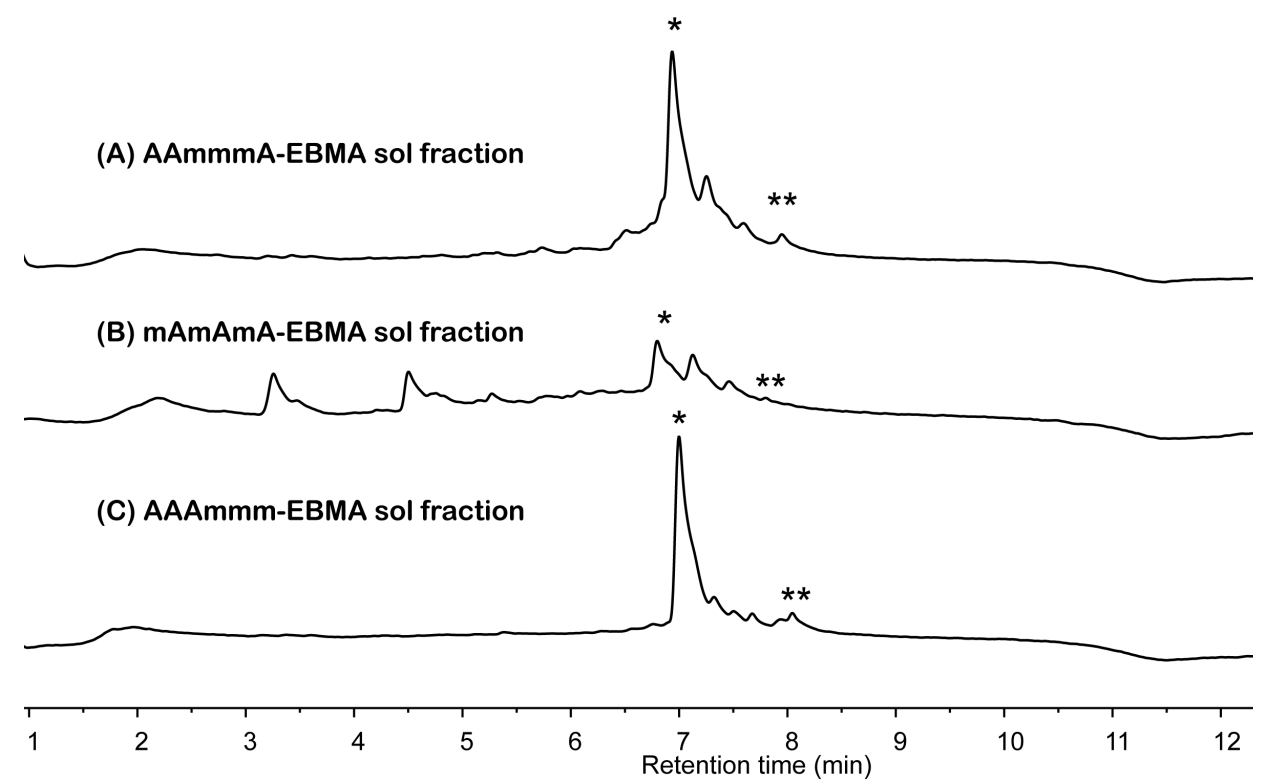

Supplementary Figure 24. Absorbance spectra at $210 \mathrm{~nm}$ from LC-MS analysis of sol fractions from 60 min networks of (A) AAmmmA-EBMA, (B) mAmAmA-EBMA, and (C) AAAmmmEBMA after being subjected to acidic cleavage solution (trifluoroacetic acid:acetonitrile:water, $1: 1: 1, \mathrm{v} / \mathrm{v} / \mathrm{v}$ ). ${ }^{*}$ Corresponds to a $\mathrm{m} / \mathrm{z}$ of $1651 \mathrm{~g} / \mathrm{mol}$ (completely modified oligomer) and ** corresponds to a $\mathrm{m} / \mathrm{z}$ of $1392 \mathrm{~g} / \mathrm{mol}$ (unmodified oligomer plus water). 


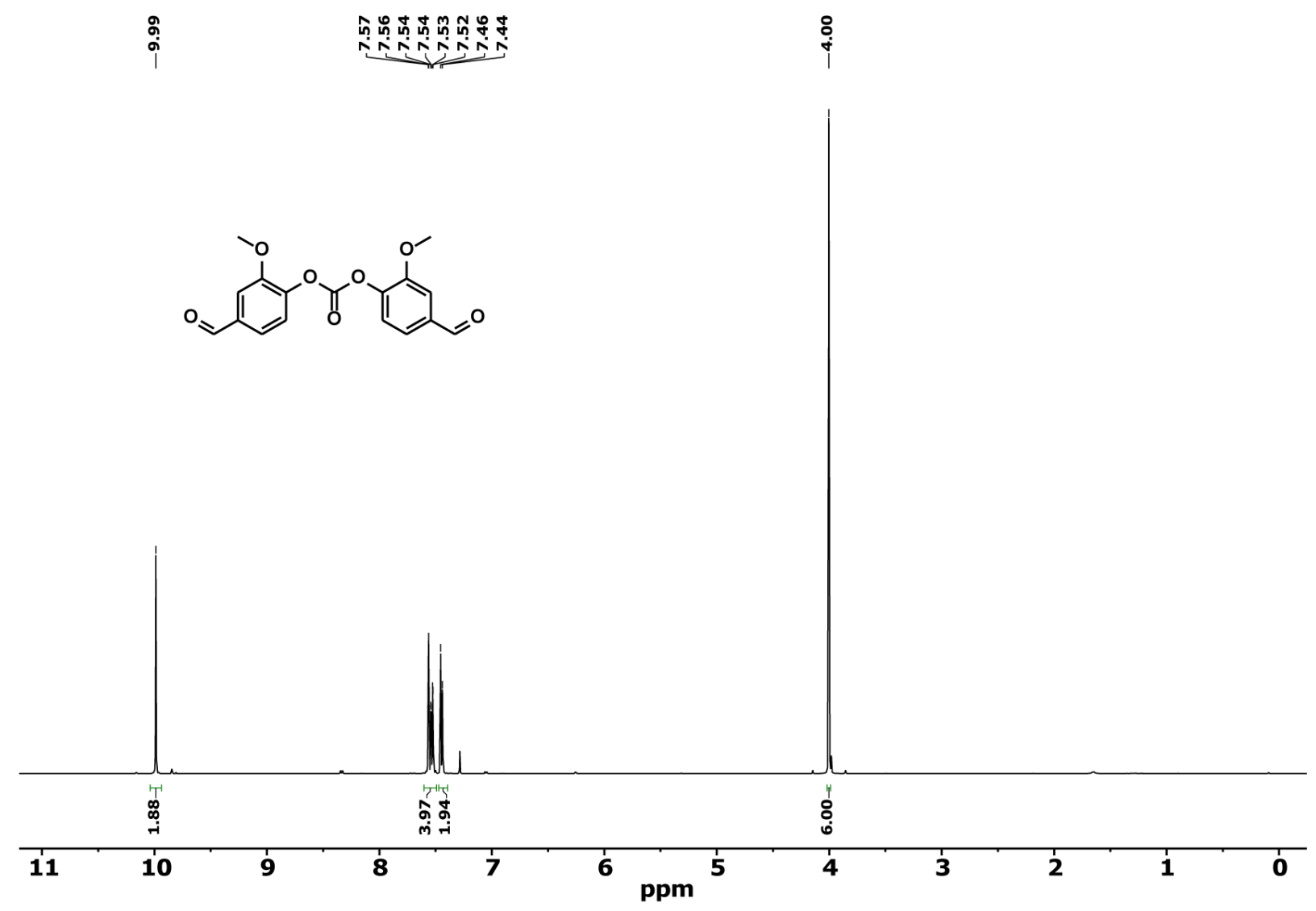

Supplementary Figure 25. ${ }^{1} \mathrm{H}$ NMR spectrum of divanillin carbonate in $\mathrm{CDCl}_{3}$. 

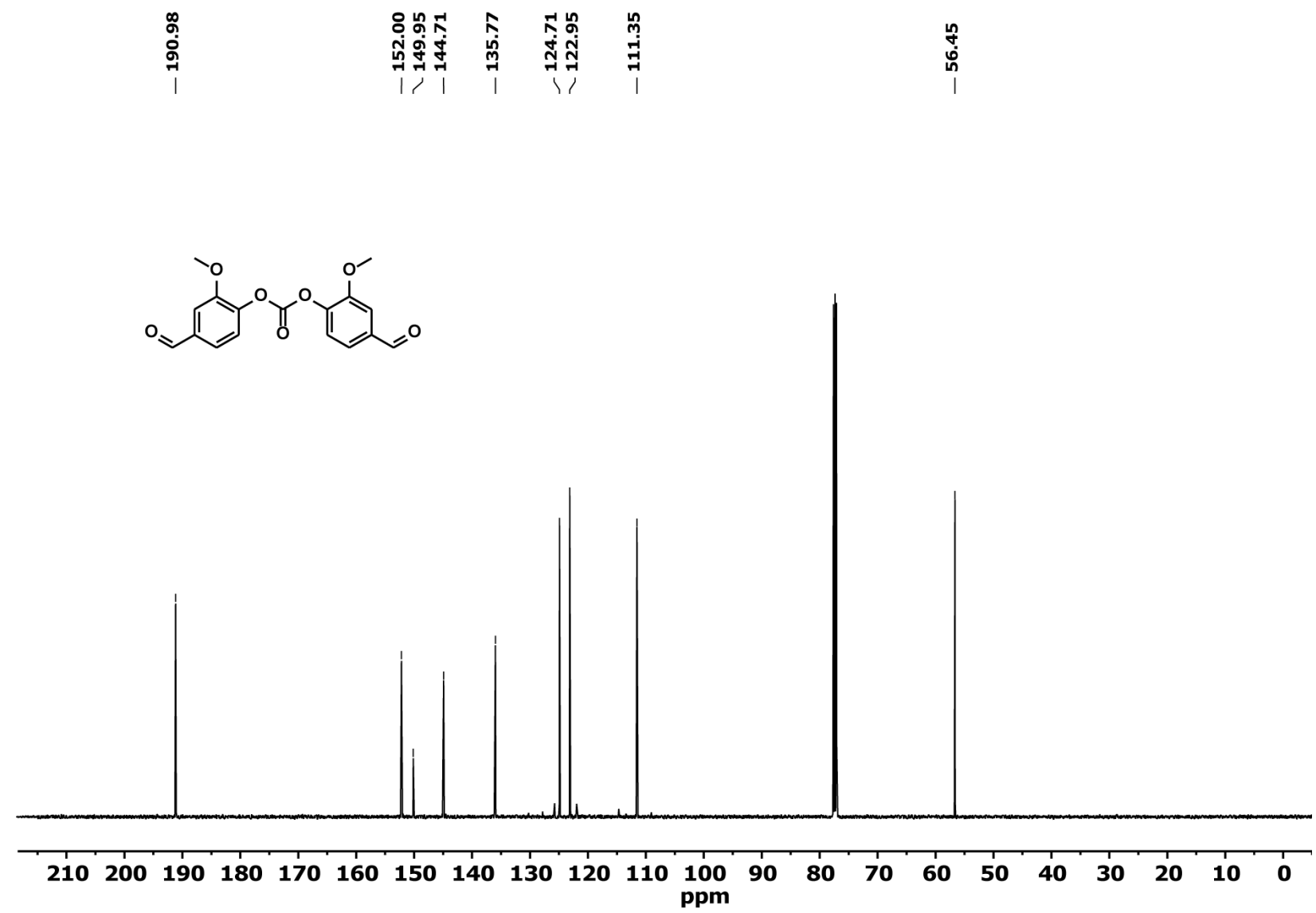

Supplementary Figure 26. ${ }^{13} \mathrm{C}$ NMR spectrum of divanillin carbonate in $\mathrm{CDCl}_{3}$. 


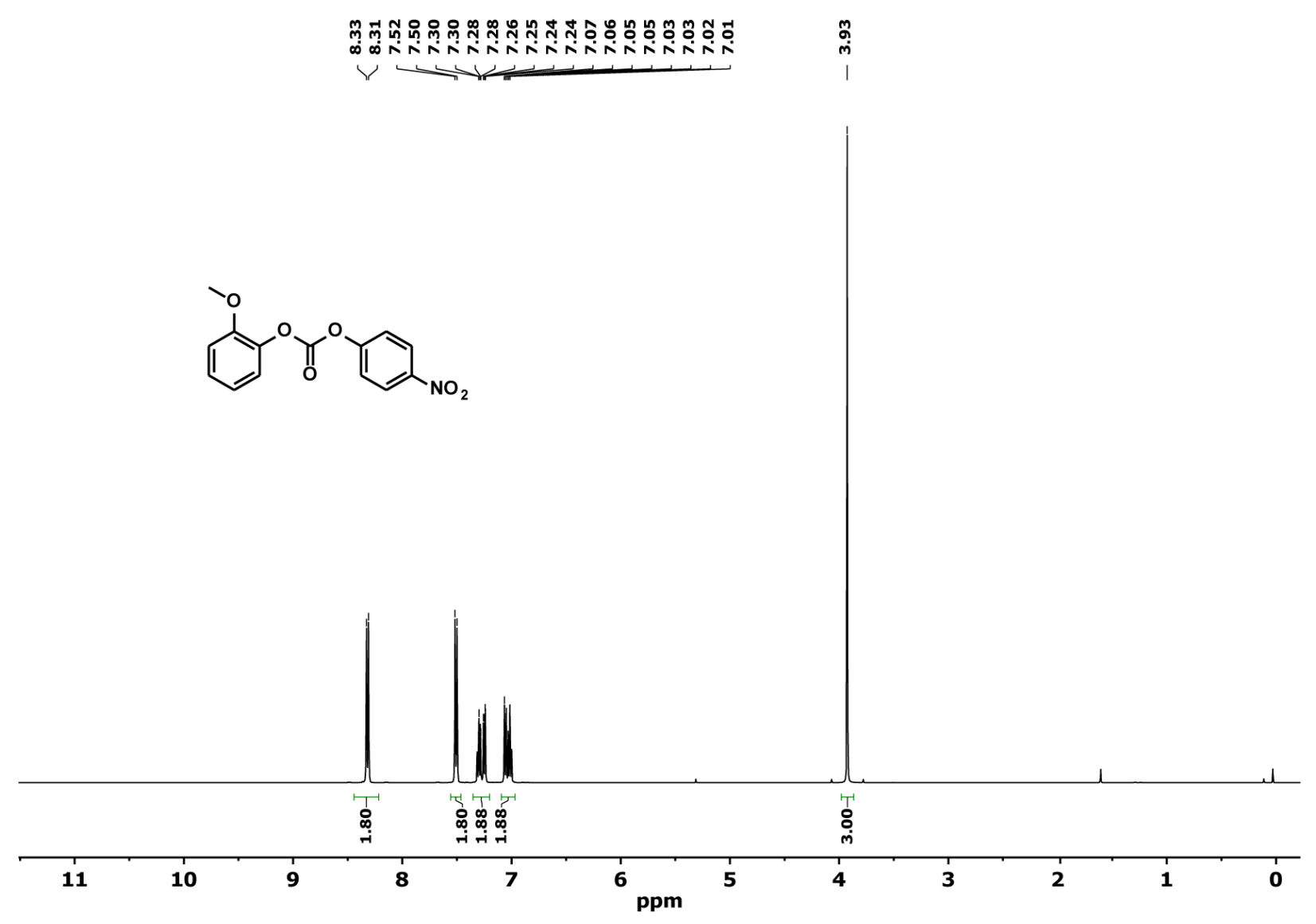

Supplementary Figure 27. ${ }^{1} \mathrm{H}$ NMR spectrum of NPC-guaiacol in $\mathrm{CDCl}_{3}$. 


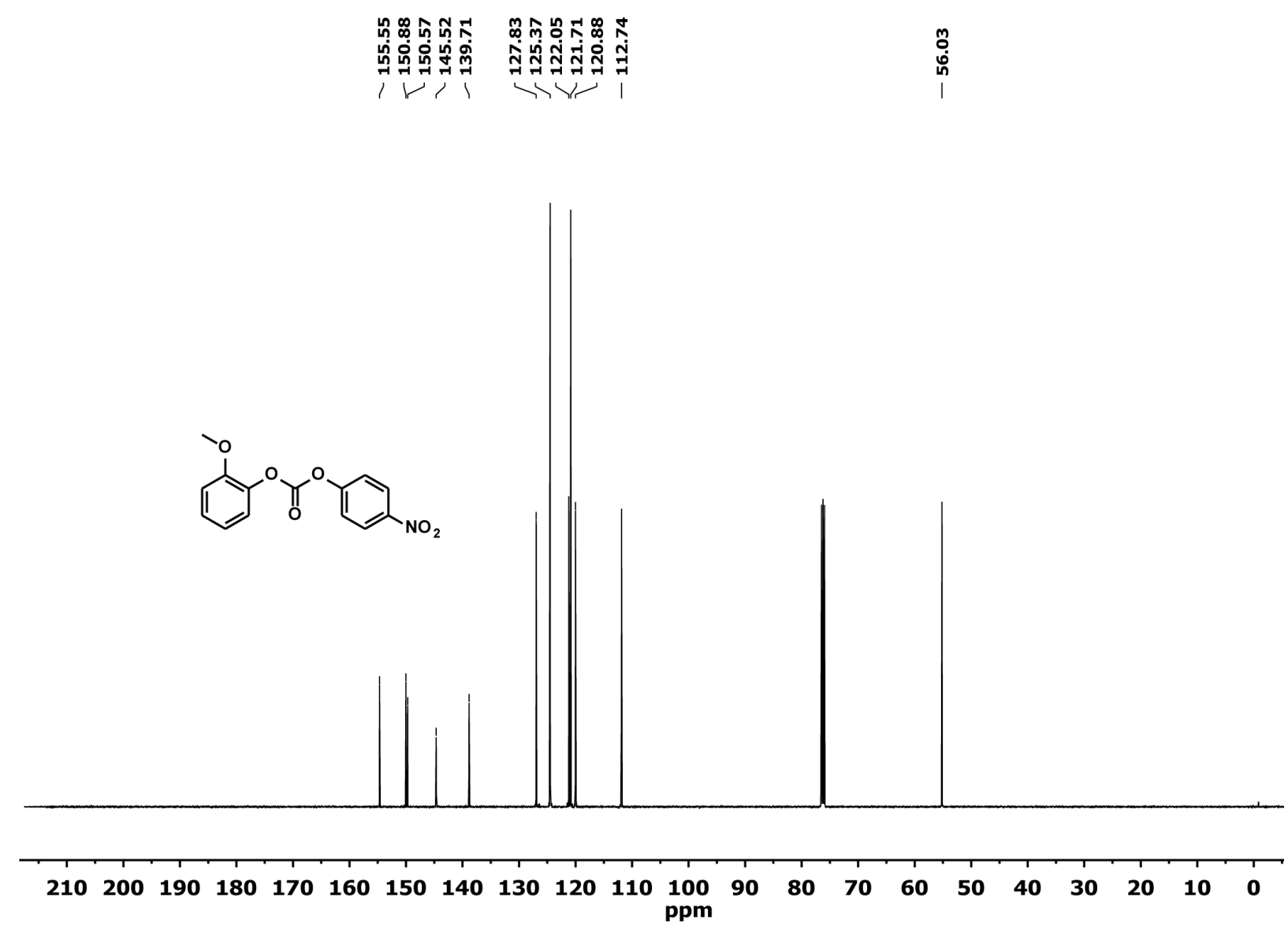

Supplementary Figure 28. ${ }^{13} \mathrm{C}$ NMR spectrum of NPC-guaiacol in $\mathrm{CDCl}_{3}$. 


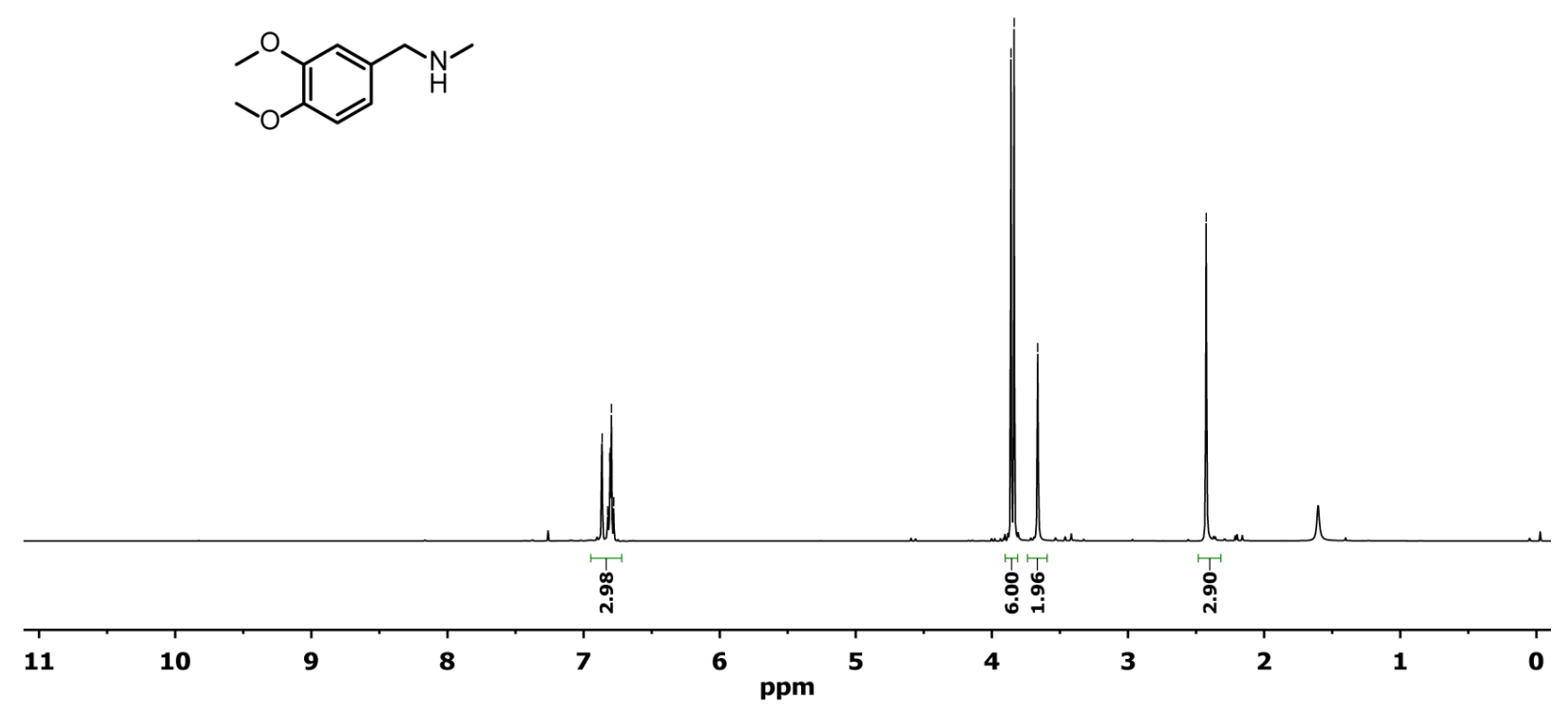

Supplementary Figure 29. ${ }^{1} \mathrm{H}$ NMR spectrum of 3,4-dimethoxy-N-methylbenzylamine (MBA) in $\mathrm{CDCl}_{3}$. 


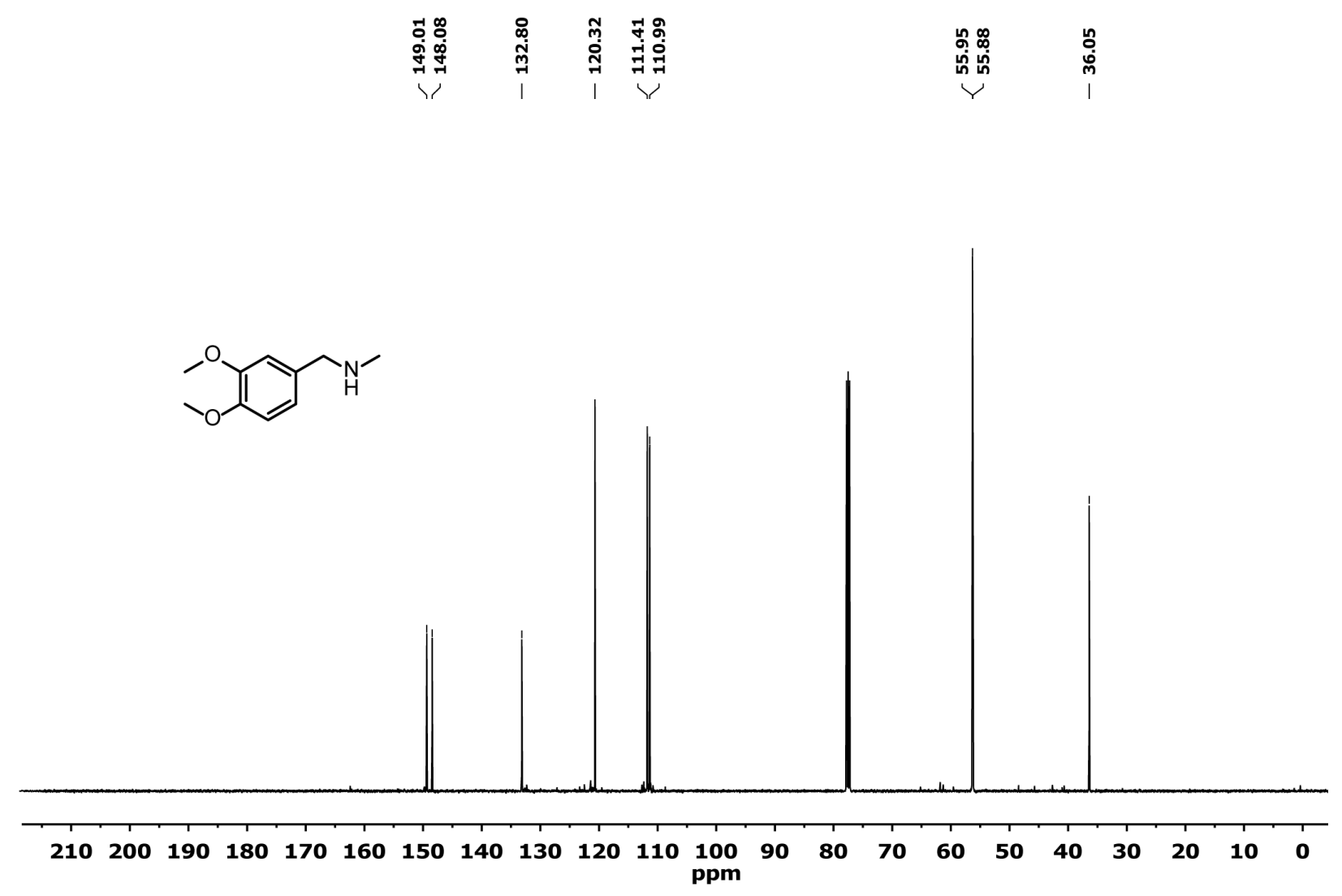

Supplementary Figure 30. ${ }^{13} \mathrm{C}$ NMR spectrum of 3,4-dimethoxy-N-methylbenzylamine (MBA) in $\mathrm{CDCl}_{3}$. 


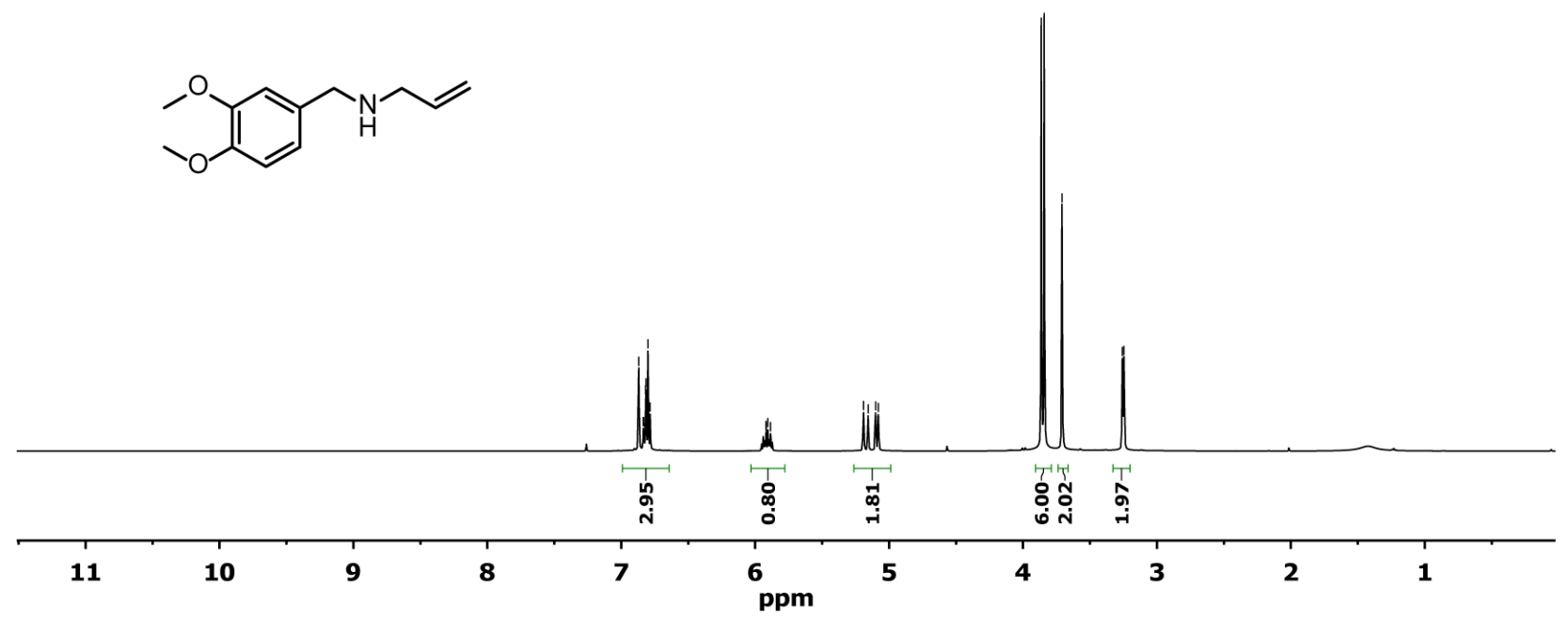

Supplementary Figure 31. ${ }^{1} \mathrm{H}$ NMR spectrum of 3,4-dimethoxy-N-allylbenzylamine (ABA) in $\mathrm{CDCl}_{3}$. 


\begin{tabular}{|c|c|c|c|}
\hline 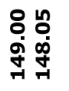 & 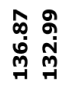 & 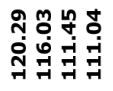 & 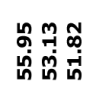 \\
\hline$\backslash$ & 11 & $1<4$ & $11 /$ \\
\hline
\end{tabular}

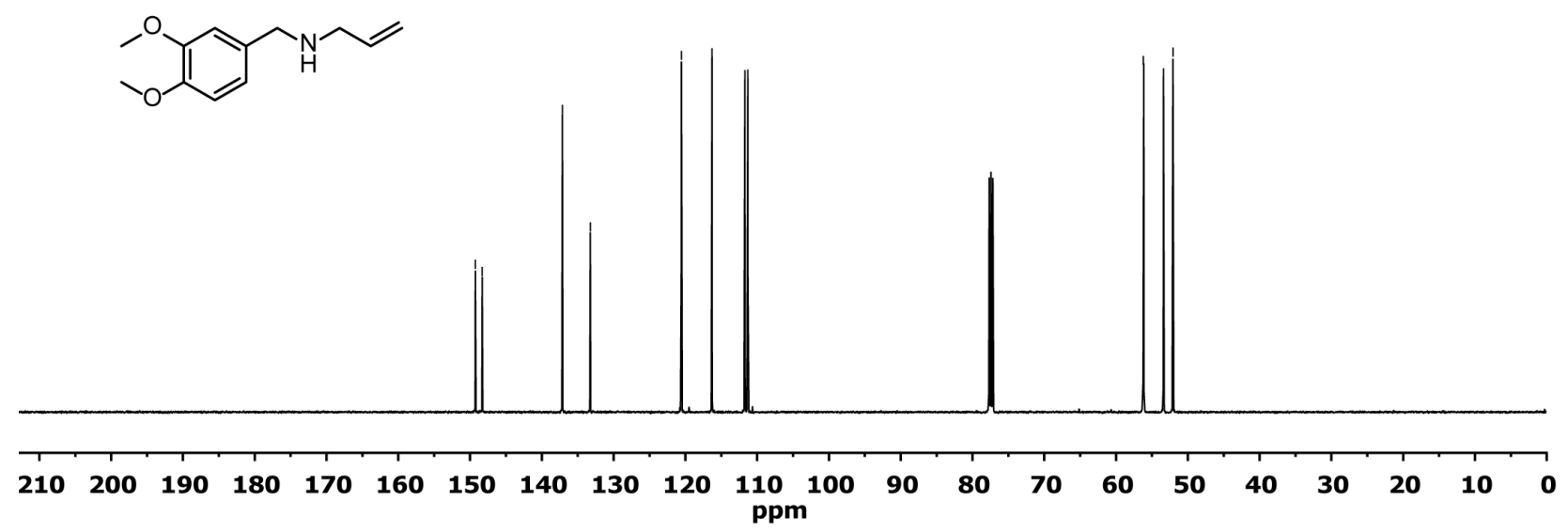

Supplementary Figure 32. ${ }^{13} \mathrm{C}$ NMR spectrum of 3,4-dimethoxy-N-allylbenzylamine (ABA) in $\mathrm{CDCl}_{3}$. 


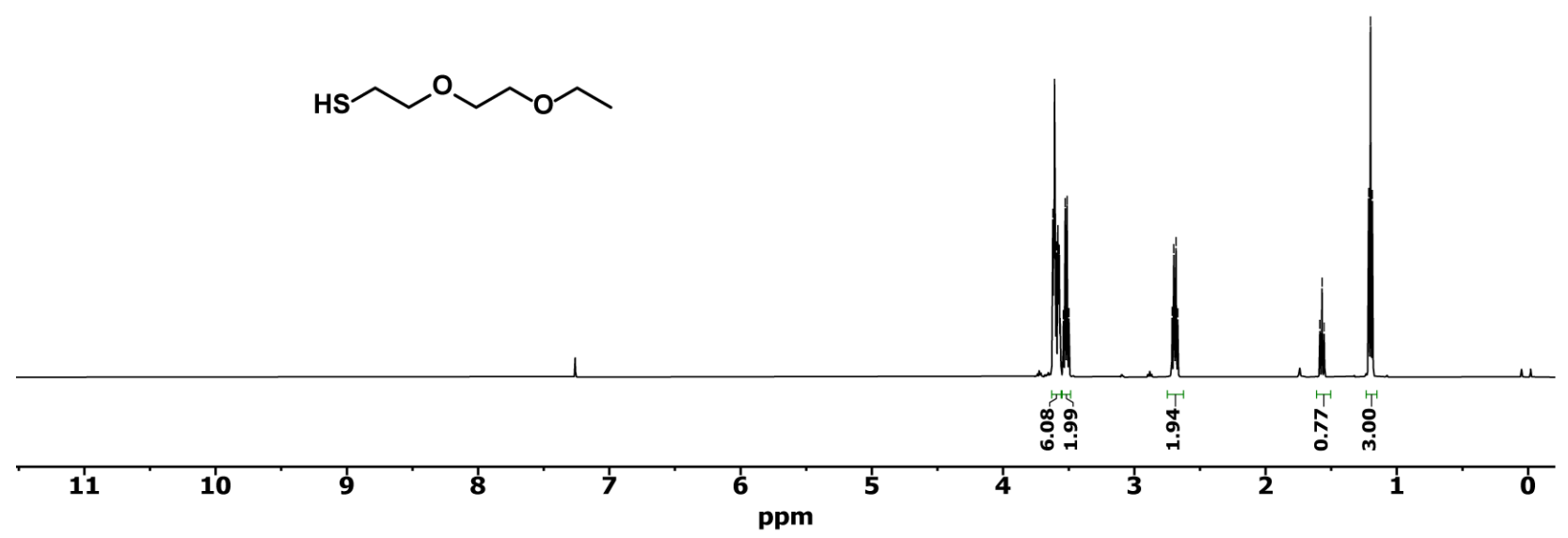

Supplementary Figure 33. ${ }^{1} \mathrm{H}$ NMR spectrum of EEET synthesized for model thiol kinetics in $\mathrm{CDCl}_{3}$. 
Hs $\sim{ }^{\circ} \widehat{O O}_{\mathrm{O}}$

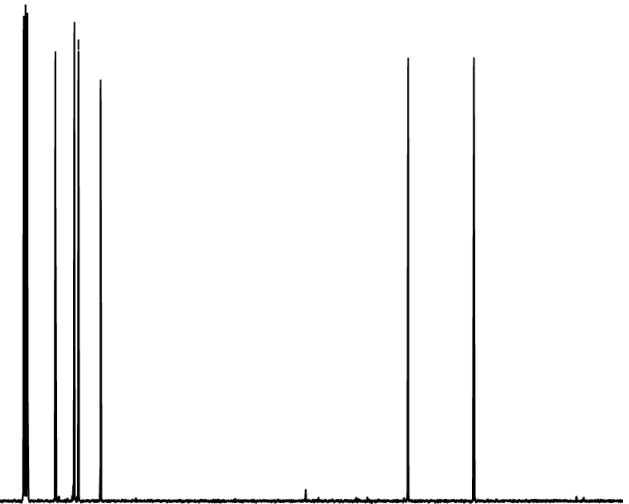

\section{$\begin{array}{llllllllllllllllllllll}210 & 200 & 190 & 180 & 170 & 160 & 150 & 140 & 130 & 120 & 110 & \underset{\mathrm{ppm}}{100} & 90 & 80 & 70 & 60 & 50 & 40 & 30 & 20 & 10 & 0\end{array}$}

Supplementary Figure 34. ${ }^{13} \mathrm{C}$ NMR spectrum of EEET synthesized for model thiol kinetics in $\mathrm{CDCl}_{3}$. 